\title{
An evaluation of seed number as a measure of fitness: a review and experimental study
}

\author{
by \\ Lina Wen
}

A thesis submitted to the Faculty of Graduate and Postdoctoral Affairs in partial fulfillment of the requirements for the degree of

Masters of Science

in

Biology

Carleton University

Ottawa, Ontario

(C) 2019, Lina Wen 


\begin{abstract}
Seed number is often used as a measure of fitness; however, situations exist where there is a discrepancy in the relationship between seed number and fitness. In Chapter 1, I identify eight main scenarios in nature where fitness is not well represented by seed count, and review existing empirical research that used seed count under these specific scenarios. Results suggest that the validity of seed number as a measure of fitness is largely under studied and should be supplemented with alternative metrics to appropriately quantify fitness. In Chapter 2, I use the monocarpic herbaceous plant Lobelia inflata to assess whether variable seasonal constraints can disrupt the relationship between seed count and fitness under controlled growth chamber conditions.

Interestingly, the relative per-seed fitness is $0.774 \pm 0.034$ under constrained compared to long season conditions; higher total fitness is observed under a constrained season using simple seed count, but not after accounting for seedling viability.
\end{abstract}




\section{Acknowledgements}

Foremost, I would like to express my sincere gratitude to my supervisor, Dr. Andrew Simons for the continuous support, guidance, and expert advice throughout the duration of my Masters studies. I am forever grateful for the knowledge I have obtained from him that shaped me into the researcher that I am today. I could not have asked for a better mentor. I would also wish to express my gratitude to the members of my advisory committee, Dr. Joseph Bennett and Dr. Jessica Forrest for their valuable suggestions and kind comments, which have contributed greatly to the improvement of this thesis. As well, I would like to acknowledge the financial support received from Andrew's NSERC Discovery Grant and from the Faculty of Graduate Studies.

Throughout my time at Carleton University, I received constant assistance from its faculty and staff members from the Department of Biology. I would like to thank following research volunteers and assistants over the past years: Mahmoud El-Saadi, Hillary Hale, Vivienne Seymour, and Kousay Kojan. I would also like to thank Dr. Shelley Hepworth for lending me the use of her growth chamber for the duration of my experiment, Ryan Chlebak for his assistance with growth chambers and seed germinators, and all other staff members that have ever given me a helping hand or a smile to brighten my day.

To the members of the Simons' lab, thank you for being the most supportive labmates I could ever have, and for the moments of laughter that I will never forget; your humble passion for research and science motivated me every day. I would like to thank 
Harry Hitsman for his genuine kindness and assistance around the lab, Winston Campeau for his humorous optimism and assistance with my data analyses, and Shravan Ram for being an inspiration and for his unwavering support throughout my graduate studies.

Finally, I would like to acknowledge my friends and family for their endless encouragement. To my family, thank you for your prayers and for your unconditional love. To Lucy Tran, thank you for reminding me of my blessings and for your faith in me. To Caner Nar, thank you for believing in me when I didn't believe in myself. You have been there every step of the way, and have helped me see the light even in the darkest of times.

And to my Mother, my biggest supporter, this is all for you. I love you. 


\section{Table of Contents}

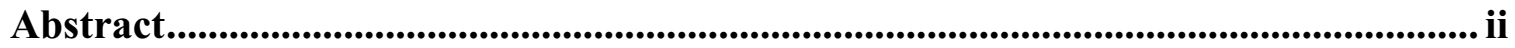

Acknowledgements ..........................................................................................................................iii

Table of Contents ........................................................................................................................... v

List of Tables ................................................................................................................................ vii

List of Figures................................................................................................................................ viii

List of Appendices.......................................................................................................................... $\mathrm{x}$

General Introduction .................................................................................................................. 1

Chapter 1: A review of seed count as a measure of fitness .............................................. 4

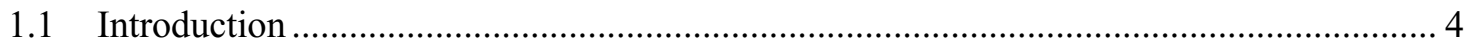

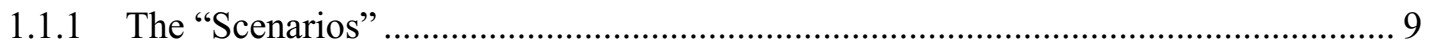

1.1.2 Methodology …………………………………………………………… 15

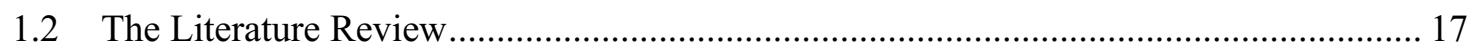

1.2.1 Distribution of studies among scenarios ................................................................... 19

1.2.2 Alternative metrics used ……………………………………………………. 23

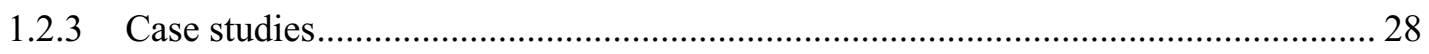

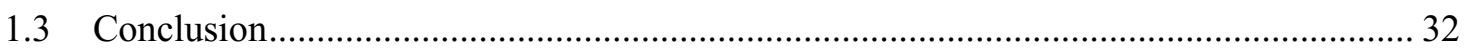

Chapter 2: Variable constraints disrupt the relationship between seed count and

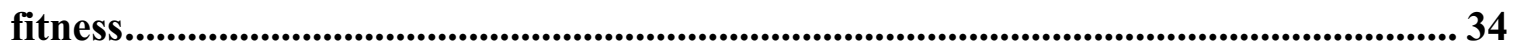

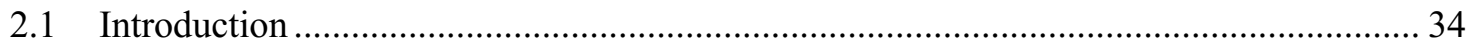

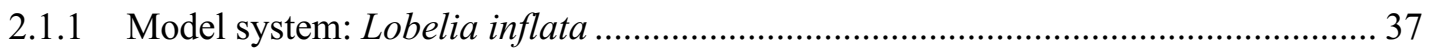

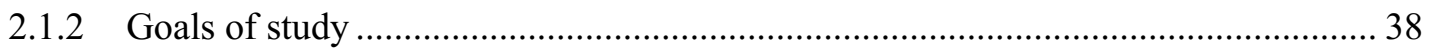

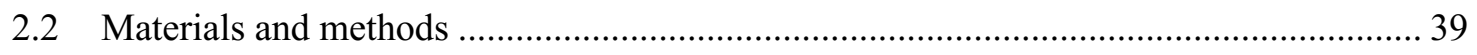

2.2.1 Lobelia inflata and field collection ....................................................................... 39 
2.2.2 Season length manipulation

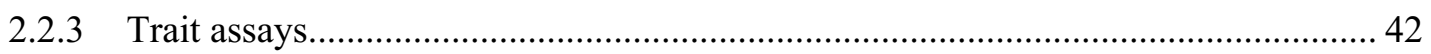

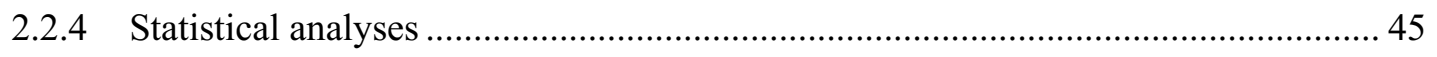

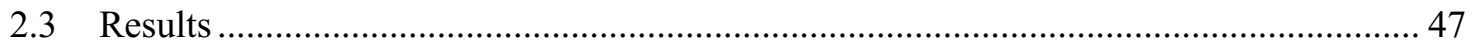

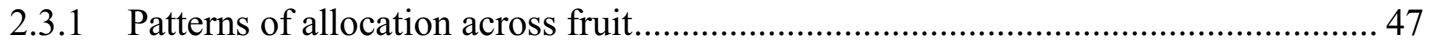

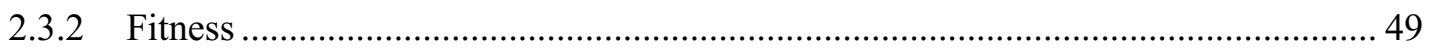

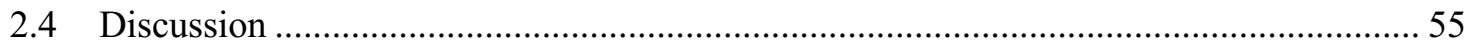

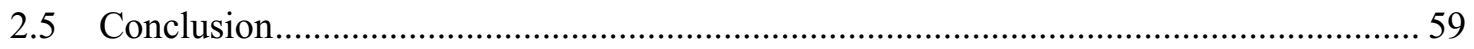

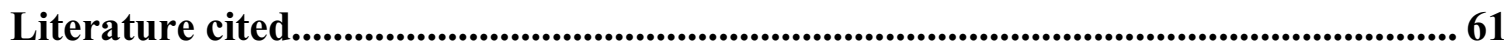

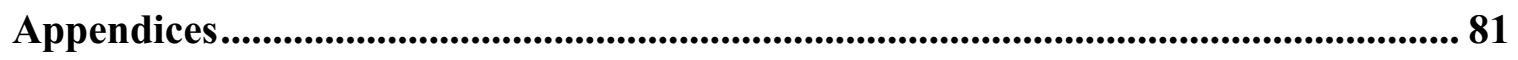

Appendix A Complete table of research articles used for the literature review ....................... 81

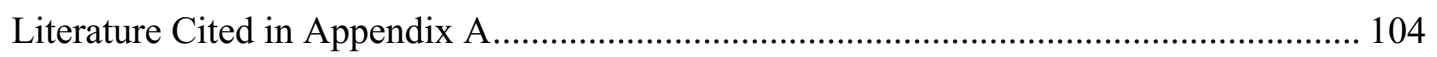

Appendix B Supporting data for the effects of salinity on germination and seed yield of

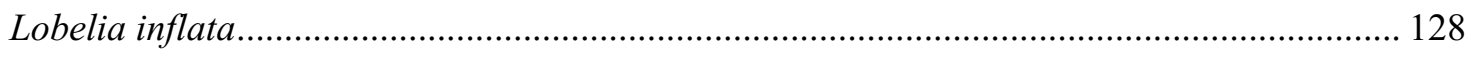




\section{List of Tables}

Table 2.1 General comparison of reproductive trait expression between two manipulated environments observed in Lobelia inflata.

Table 2.2 Sources of variation in reproductive traits (fruit size, seed number, seed size) across three fruit positions (FP) and two environments (ENV).

Table 2.3 Exploratory quadratic regressions of fruit size allocation (where fruit size is standardized to mean of 1 for each individual) on relative fruit position for all fruits produced on the main stem

Table 2.4 ANOVA results for sources of variation in germination fraction, mean germination time, and survival fraction across positions in the two contrasting growthchamber environments.

Table 2.5 Post-hoc Tukey test results for differences in means in survival between groups and across positions in the two growth-chamber environments. Letters that are not shared indicate significant different mean values.

Table 2.6 Sources of variation in germination and survival fraction as an effect of seed size nested within fruit position in the two environments. Results of a mixed effects logistic regression using the subset of seeds individually tracked for survival, germination and size. 


\section{List of Figures}

Figure 1.1 An area graph showing the number of studies that have used seed number as a measure of plant fitness, the number of studies that have acknowledged that seed number may be a biased estimate of plant fitness, the number of studies that have justified seed number as a measure of fitness, and the number of studies that have suggested solutions to problems with using seed count as a measure of fitness

Figure 1.2 A Venn diagram showing the overlap between the different "scenarios". The size of each circle represents the number of studies in each scenario. $\mathrm{PA}=$ plant architecture, $\mathrm{HB}=$ trade-offs between allocation in reproduction and defense against herbivory, $\mathrm{MF}=$ male and female success, $\mathrm{SO}=$ selfed vs. outcrossed progeny, $\mathrm{SA}=$ sexual vs. asexual reproduction, $\mathrm{VP}=$ variation in phenology, $\mathrm{VI}=$ variation in degree of iteroparity, $\mathrm{BH}=$ bet hedging

Figure 1.3 Breakdown of reviewed studies into categories of recognition of problems associated with using seed count as a proxy for fitness under each "scenario". The total number of studies that have investigated plant fitness are represented by the dark blue bar, studies that have acknowledged seed count as a biased measure of fitness in red, studies that have justified seed number as a measure of fitness in green, studies that have suggested solutions in purple, and studies that have suggested solutions in light blue. Some of the 147 studies examined fall under multiple scenarios, and each occurrence is included in this analysis; therefore, the total number of studies exceeds 147. See Figure 1.2 for scenario abbreviations. .................................................................................................... 21

Figure 1.4 Pie charts showing the percentage of all studies that have exclusively used seed number as a measure of fitness and the percentage of studies that have used an alternative measure of fitness with or instead of seed count. The second pie chart represents the percentage of various alternative fitness metrics used in studies that have used an alternative metric with or instead of seed count ...................................................... 23

Figure 1.5 Sunburst chart showing the proportions of alternative fitness metrics to seed count used under each scenario (see Fig. 1.2 for scenario abbreviations). The abbreviations for the alternative fitness metrics are: $\mathrm{PB}=$ plant biomass, $\mathrm{SS}=$ seed size, 
$\mathrm{TSM}=$ total seed biomass, GERM= germination success, $\mathrm{SURV}=$ survival, $\mathrm{SE}=$ seedling

establishment, and $\mathrm{MS}=$ male success ..................................................................... 25

Figure 2.1 Average fitness estimates based on pure seed count and "true fitness" that accounts for successful seed germination and survival, measured across the two manipulated environments. A) Seeds from main stem fruits, and B) Seeds from all fruits, including branched fruits. Solid lines $=$ true fitness, dashed lines $=$ pure seed count. Error bars represent standard error. ................................................................................. 54 


\section{List of Appendices}

Appendix A Complete table of research articles used for the literature review ............... 83

Appendix B Supporting data for the effects of salinity on germination and seed yield of

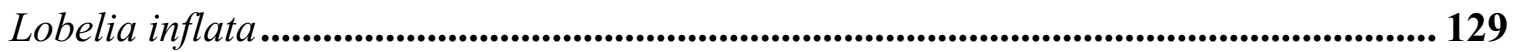




\section{General Introduction}

Fitness is a key concept in evolutionary biology and may be represented as the ability to survive and reproduce. Unfortunately, it is notoriously difficult to define and measure fitness (Dobzhansky, 1955; Kempthorne and Pollak, 1970; Wagner, 2009). Despite its central role, there is no universally accepted method to measure individual fitness. Endler (1986) famously discussed five classic definitions of fitness (Darwinian fitness, the natural selection rate coefficient, adaptedness, adaptability, and durability), each containing unique properties. Although there are differences in what these fitness concepts represent, all of them aim to quantify a rate of increase, and that is typically achieved by estimating the relative number of offspring produced per individual (Stearns, 1992; McGraw and Caswell, 1996; Godfrey-Smith, 2007).

In plant biology, a large number of studies have focused on seed production as a measure of fitness under the assumption that seed number is an indication of total recruitment (Pan \& Price, 2002; Aarssen, 2014; Simons \& Johnston, 2000a). Seed number is often used as a measure of fitness because it is a direct measure of reproductive success and is easily quantified (Primack and Kang, 1989). However, there are several scenarios in nature where there is a "disruption" between the relationship of seed number and fitness. Evolutionary theorists have recognized the pitfalls of solely using seed number as a measure of fitness (Primack and Kang; 1989; Eriksson and Jerling, 1990), and while this problem has been acknowledged in recent studies (Metsare et al., 2015; Austen and Weis, 2016; Bigio et al., 2017), no study to date has explicitly identified 
situations where seed number may not be a reliable proxy for fitness, or recognized alternative measures that should be taken in those particular situations.

In this thesis, I focus on the question of whether seed number is a reliable estimate of plant fitness, by conducting two studies:

1) A literature study that identifies eight main scenarios in nature where fitness may not be well represented by seed number, and reviews existing empirical research for the use of seed number as a measure of fitness under these specific scenarios.

2) An empirical study to test one of these scenarios; specifically that variation in phenology under different quality growth conditions influences the relationship between seed count and fitness.

The first objective of the literature review is to describe the main scenarios in nature where seed count may not be a reliable measure of fitness. The second objective is to review existing empirical studies for the use of seed count as a proxy for fitness under the scenarios identified, have acknowledged that seed number may not be a reliable measure of fitness, have justified the use of seed count, or have used alternative or additional measures of fitness. The term "scenarios" will be used to describe circumstances or situations in which seed number is not a reliable measure of fitness, and the term "disruption" will be used to describe the disconnect between seed number and fitness under these scenarios. 
For the empirical study, I use the monocarpic herbaceous plant Lobelia inflata (Campanulaceae) to assess whether variable constraints imposed by season length can disrupt the relationship between seed count and fitness. Although seed number might not be reduced under a constrained season length (Hughes and Simons 2014a), fitness costs may result from a reduction in seed quality. Plants that experience a long season will transition from vegetative to reproductive mode at a larger size, and might produce better quality seeds than a plant that has been forced to accelerate its development under a short season. Thus, together with evidence that late bolting plants show a progressive semelparous reproductive strategy (Hughes and Simons, 2014a), it seems reasonable to infer that a trade off in seed number and seed quality will occur.

The goals of the two chapters are to investigate situations in which seed number may be a biased estimate of fitness, and to provide solutions for when there are confounding effects on the relationship between seed number and fitness. This is important because investigators can be aware of the potential consequences of using seed number as a measure of fitness when conducting experimental or observational studies. This thesis addresses fundamental questions about the estimation of plant fitness, and provides insight on more suitable alternatives that can be used when feasible. 


\section{Chapter 1: A review of seed count as a measure of fitness}

\subsection{Introduction}

Fitness is a fundamental concept in evolutionary theory and is meant to reflect the probability of survival and reproduction. One of the important reasons we measure fitness is to determine the strength of selection acting on life history traits, and how the differential expression of these traits result in evolutionary change and adaptation (Williams, 1966; Endler, 1968; Stearns, 1976; Mills and Beatty, 1979; Sober, 1984; Sober, 2001; Barker, 2009). Assessment of the pattern and strength of selection requires measuring the association of fitness to a particular property or trait of an individual (Lewontin, 1970; Lande and Arnold, 1983; Arnold and Wade 1984; Roff, 1992).

The fitness concept can vary among different fields of biology (i.e. in demography, quantitative genetics, population genetics developmental and physiological, systematics, comparative biology studies) (Brommer, 2000; Metz, 2008; Hansen, 2017), and the literature on the topic is vast. Reviews exist on the various ways in which the term is used across contexts (i.e. genes, genotypes, individuals, groups) (Hedrick and Murray, 1983, Endler, 1986). A widely used fitness metric is the intrinsic rate of increase, or "Malthusian parameter" (r), a measure of the per capita instantaneous rate of increase of a genotype or population with a stable age distribution (Stearns, 1992, Brommer, 2000). Net reproductive rate, $\mathrm{R}_{0}$, is the combination of age-specific survival and reproductive rates, and has been favoured by field biologists interested in variation in reproductive success (Endler, 1986; Brommer, 2000). 
In contrast to $\mathrm{r}$ and $\mathrm{R}_{0}$, Rand et al. (1994) have based a fitness concept on the invasibility criterion in the context of evolutionarily stable strategies (ESS) (Metz et al., 1992; Geritz et al., 1998; Brommer, 2000). Furthermore, fitness may be expressed either as absolute or relative fitness. Absolute fitness measures the proportional growth (positive or negative) of a unit of selection (e.g. genotype), while relative fitness is success in comparison to either the mean fitness, or the fittest genotype in the population (Kimbrough, 1970; Orr, 2009). Individual fitness may also be measured across several generations. It may be quantified as the mean fitness; however, reproduction is a multiplicative process, and the long-term fitness of a genotype should be quantified as the geometric mean of individual fitness values (Roff, 2002; Wagner, 2010; Chevin, 2011; Starrfelt and Koko, 2012). Although each of these fitness concepts has different properties, the common goal is to quantify a rate of increase.

Regardless of the lack of a single theoretical fitness concept, evolutionary biologists must quantify fitness in empirical studies (Godfrey-Smith, 2009; Sober, 2001). Approaches to empirical measures of fitness are also diverse, and also differ among fields of biology. Studies in demography use age and size-specific variation in mortality and reproduction to infer fitness (Stearns, 1992; McGraw and Caswell, 1996; Engen and Sæther, 2014), whereas quantitative genetics studies focus on selection differentials and trait correlations with fitness (Lande, 1982). In population genetics, fitness differences are quantified at the genetic level and are expressed in terms of a change in allele frequency at individual loci (je Jong, 1994; Barker 2009). 
Evaluating fitness is straightforward in some organisms, and especially so in some plants. For evolutionary studies, it is helpful to work with organisms that reproduce quickly, so fitness can be assessed across an entire, or several lifetimes. For example, in clonal populations of microbes, one commonly used method of quantifying fitness is to calculate the maximum growth rate (Vmax) of a culture by measuring the optical density of the culture over time (Andersson and Hughes, 2010, Wiser and Lenski, 2013). There are several advantages of these methods; for example, a spectrophotometer can measure many samples quickly and efficiently, and systems can be programmed to take measurements of a full growth cycle of a culture (Wiser and Lenski, 2013).

It is more difficult to measure long-term reproductive success in longer-lived organisms, and researchers will often use a proxy for fitness. For example, insects have several traits that can be used as fitness proxies: size, longevity, fecundity, mating ability and vagility. All these proxies are positively correlated with the lifetime fitness of an individual (Doyon and Boivin, 2005). In more complex organisms such as mammals, body condition indices are frequently used as surrogate of fitness and are generally positively related to fitness (Green, 2001; Milenkaya et al., 2015).

Fitness assessment in plants is facilitated by several factors. First, plants are sessile, facilitating studies of growth, survival and reproduction (Primack and Kang, 1989). Second, they can be grown in controlled conditions. Moreover, genetically identical replicates can often be obtained by cloning, which can be beneficial in 
determining environmental effects on the trait(s) under investigation. Last, plants have a diversity of sexual systems that can be used to study the genetic and morphological mechanisms on differential fitness patterns (Bawa and Beach, 1981). In experimental studies, several traits can readily be used as proxies for fitness (i.e. biomass, size, or performance), but fitness is most commonly represented as lifetime seed production (Strauss, 1997, Geber and Griffen 2003, Younginger, 2017).

Seed number is often used as a measure of fitness for many reasons; most notably, it can be readily counted (Pan and Price, 2002). However, there is a strong underlying assumption that seed count accurately represents (relative) fitness. In current literature, there is seldom a justification for the use of seed number as a reliable method for estimating fitness, and there are reasons to suspect that seed number might provide a biased estimate of fitness under a variety of circumstances.

There are several scenarios in nature where there is a 'disruption' in the relationship between seed number and fitness. For example, for individuals that can reproduce both sexually and asexually, seed number may not be an appropriate measure of fitness as it only represents the sexual component of fitness (Antonovics and Ellstrand, 1984, Aarssen, 2014). Thus, the validity of the assumption that seed count is an accurate measure of fitness is not universal. 


\section{This review will aim to:}

1. Outline the main scenarios in nature in which seed count may not be an appropriate measure of fitness.

2. Provide evidence from published studies for the use of seed count as a measure of fitness, and quantify the number of studies that have acknowledged that seed count may be a biased estimate of fitness, justified the use of seed count as a proxy for fitness, provided solutions to problems with using seed count as a measure of fitness, or have offered alternative metrics.

3. Establish appropriate experimental criteria to evaluate which specific metrics most accurately reflect fitness and consider the appropriate methodological and experimental requirements to measure fitness in plant populations. 


\subsubsection{The "Scenarios"}

Here, I identify eight main scenarios in nature in which the relationship between seed number and fitness may be disrupted. It is worth noting that these eight scenarios do not represent the entirety of possible scenarios, but are the most prominent in current literature; nor are they mutually exclusive. They can fall into broader categories of tradeoffs, environmental heterogeneity, and differential reproductive modes.

\section{Trade-offs}

\section{i. Plant architecture}

Plant form may be variable within species (e.g. height, degree of branching). Architecture may influence fitness, through factors such as dispersal, independent of seed number. For instance, height would confer a fitness advantage for several reasons: by attracting greater pollinator visitation, thus allowing larger pollen loads and producing more vigorous offspring (Donnelly et al., 1998); through more effective pollen and seed dispersal (Lortie and Aarssen, 1999); through variation in susceptibility to herbivore damage (Cipollini and Bergelson, 2002); or through competition for light (Aarssen, 2008). Trade-offs in resource allocation between reproductive versus vegetative function may also affect fitness (Charnov, 1982; Reekie and Bazzaz, 1987; Taylor et al., 1990). A plant that invests more into vegetative growth might suffer in reproductive output in terms of number and quality. For instance, plants that invest in interference strategies (i.e. 
allocating more into stem and leaf growth to shade neighbours) might produce fewer seeds than a plant that allocates primarily to reproduction (Falster and Westoby 2003; de Jong and Klinkhamer, 2005). Thus, because of differences in plant architecture among individuals, counting seeds may not be an accurate representation of fitness, and should be used with another fitness measure such as plant biomass.

\section{ii. Trade-offs between defense against herbivory and seed number}

Interactions of herbivores with plant reproductive tissues can cause negative effects on plant fitness (Feeny, 1976; Bazzaz et al.,1987, McArt et al., 2013). If variation in allocation to defense against herbivory exists among individuals, seed count of defended individuals would underrepresent their relative fitness. For example, plants can allocate more energy to chemical defenses to avoid predators, and in turn produce fewer seeds that are more protected and fitter (Lehndal and Agren, 2015). Results from a metaanalysis demonstrate that the production of antiherbivore defenses imposes a fitness cost on plants through negative correlations between defense and fitness measures (Koricheva, 2002). This analysis also suggests that fitness costs may arise not only due to trade-offs in the allocation of common limited resources between defense, growth and reproduction within an individual plant, but also through interactions between plants and external factors in their environment. For instance, plant responses to herbivory may cause changes in floral attraction, which can then affect seed production indirectly through attractiveness to pollinators (Strauss, 1997). Thus, these results suggest that seed 
number may not be an appropriate measure of fitness due differences in allocation, and should be supplemented with metrics reflecting growth and defense.

\section{iii. Bet-hedging}

Bet-hedging strategies are expected to evolve that maximize geometric-mean fitness rather than maximizing fitness under average conditions (Seger and Brockmann 1987; Philippi and Seger 1989; Simons 2002). Plants with relatively low apparent fitness in particular generations might produce more offspring in the long run if they express traits that reduce inter-generational variance in fitness. A classic example is delayed germination in desert plants, where spreading germination over multiple seasons can reduce the risk of complete seedling mortality from unfavourable conditions in a particular year (Cohen 1966; Venable 2007). If all seeds germinate in a single year, 100\% mortality may result if environmental conditions are particularly harsh in that year (e.g. a drought). In fact, in many temperate and tropical species, seeds do not germinate despite conducive conditions but remain dormant as a risk-reducing strategy in unpredictable environments (Liu, 2014, Simons and Johnston, 2006). Therefore, seed count may not be a reliable measure of fitness when plants use bet-hedging strategies. An appropriate measure of fitness for plants expressing bet-hedging strategies would include measuring fitness across several generations. 
iv. Variation in degree of iteroparity

An iteroparous species may divide its resources between reproduction and somatic maintenance; individuals that allocate more energy to reproduction might suffer lower residual reproductive value. Thus, a trade-off can occur between reproduction and survival when the degree of somatic maintenance affects the reproductive success of the parent (Young, 1981). For example, in colder months, plants that overwinter can allocate more energy to storage reserves (somatic maintenance) rather than seed production as a trade-off between vegetative and reproductive strategies (Lu et al., 2015). Therefore, assessing fitness as seed production may be inaccurate for iteroparous species, as current reproduction is only one component of the overall fitness of an individual. In order to examine how effects on different components of fitness are translated into effects on overall fitness, it is necessary to assess the entire life cycle of an individual and to include lifetime seed production (Garcia and Ehrlen, 2002).

\section{Differential modes of reproduction}

\section{v. Selfing vs. outcrossed progeny}

Plants with mixed mating systems produce variable ratios of self-fertilized and outcrossed seeds, which may differ in fitness. Self-fertilization may be favoured in the short term and often results in a larger number of offspring than outcrossing; however, 
there are fitness consequences associated with self-fertilization including inbreeding depression, which is the reduced fitness of inbred progeny relative to outcrossed progeny (Charlesworth and Willis, 2009). A meta-analysis of inbreeding depression in various fitness components showed differential inbreeding depression between self-compatible species and self-incompatible species (Angeloni et al., 2011). Thus, seed count may not represent fitness under mixed mating, because individuals will vary in their degree of inbreeding and inbreeding depression. The relationship between outcrossing and fitness can be complex: a study by Ghazoul (2014) suggests that, according to the sacrificial sibling hypothesis, nonviable seed set enhances plant fitness. Inbred seeds can be retained and used as a sacrifice during seed predator attacks for the benefit of outcrossed seeds, therefore increasing individual fitness. Therefore an assessment of survivability or seedling establishment of offspring should be used with seed number for plants with mixed mating systems.

\section{vi. Sexual vs. asexual reproduction}

Many plants exhibit dual reproductive strategies, where they can reproduce sexually, producing seeds, and asexually, through vegetative reproduction or apomixis (Askers and Jerling, 1992). Vegetative reproduction exploits a variety of plant structures to initiate new generations (e.g. budding from roots, rhizomes, stems, bulbils, or storage organs) (Eckert, 1999). Thus, seed number may not be reflective of overall fitness because it only represents one component of fitness. A complete measure of fitness 
would include other measures such as plant biomass, or parentage analyses to assess the relative success of sexually vs. asexually reproducing individuals (Silvertown, 2008).

\section{vii. Male and female success}

Since all sexually reproducing plants have a maternal and paternal parent, it is important to account for the male component of reproduction. Female fitness can be readily estimated by the number of seeds that an individual produces (Burd et al., 2009). However, male fitness, or the numbers of seeds sired by pollen, accounts for half of the genes contributed to the next generation (Sutherland and Delph, 1984). Thus, the exclusive use of seed production is a female-biased view because success as a male parent is not reflected in an individual's seed count when plants outcross. Determining male fitness can be difficult in the field. However, there are several methods available to obtain measures of male fitness: through an evaluation of the number, viability, and growth of pollen (Delph et al., 1998); and through molecular methods such as the combination of genetic markers with paternity analysis (Meagher 1986; McGraw \& Caswell, 1996). With the use of these methods and seed count, fitness of sexually reproducing plants can be obtained.

\section{Environmental heterogeneity}

viii. Variation in phenology 
The seasonal timing of growth and reproduction can cause differences in fitness among individuals in many ways (Galen and Stanton, 1991, Forrest and Miller-Rushing, 2010). Delays in phenology can result in diminishing time available for reproduction, leading to variable seed production and seed quality. For example, a plant may produce many seeds in a constrained season, but those seeds may be of lower quality because of constrained time for allocation to reproduction (see Chapter 2, p. 34). Thus, seed number may not be a reliable measure of fitness when there is variation in phenology because seed quality may be reduced. A measure of seedling survival may provide a more accurate depiction of overall fitness.

\subsubsection{Methodology}

In this review paper, I attempt to assess the prevalence of the use of seed number as a measure of fitness in published research. I performed this review to clarify which metrics are frequently used to estimate plant fitness and also to determine if the use of seed number as a measure of fitness correlates with alternative metrics in the estimation of plant fitness. I am not claiming that the use of seed number is more or less valuable than other metrics of plant fitness, nor is this meant to be an exhaustive review of the papers published that have examined plant fitness; rather, it is meant to be a

representative sample. In order to retrieve relevant papers, I attempted to filter for studies that used seed number or other metrics to examine plant fitness using Web of Science and Google Scholar databases. I used the strict combination of the following search terms for 
keyword and abstract searching: 'plant fitness' and 'offspring quality' and also screened reference lists of collected articles to obtain additional relevant papers. I only included peer-reviewed research papers from established journals and excluded any review or opinion papers, or papers that did not measure plant fitness; some papers examined herbivore fitness or were outside of biological sciences; these were not included. No priority was given to specific journals, authors, or year of publication, which ranged from 1975- 2018.

The final data set consisted of information from 147 articles that were assessed at the full-text level and sorted into eight scenarios based on two criteria of relevance to each scenario: i) assessing the goal of measuring fitness as explained by the author, and ii) identifying the natural history of the plant system used in the study. The author's reasoning behind measuring plant fitness was the main determinant of the relevance of the study to the scenario it was sorted into. I provide a critical analysis of the experimental methodologies that have been used to assess fitness in plants, justified seed count as a measure of fitness, and provided solutions to measuring total plant fitness. Alternative measures of fitness were noted and classified into seven trait categories: plant biomass, total seed biomass, seed size, germinability, survival, male success, and seedling establishment. Fruit number, fruit size and flower number are surrogates for seed number, and thus were treated as estimates of seed production. All of the studies used in this review and the categories of their fitness estimations are included in Appendix A. 


\subsection{The Literature Review}

The literature review reveals that $83.7 \%$ of studies (123/147) have used seed number (or a surrogate of seed number) as a measure of fitness (Figure 1.1). Although the review is not exhaustive, this suggests that seed number is the most frequently used measure of fitness in plant evolutionary studies, likely because it is assumed to be closely related to reproductive success (Primack and Kang, 1986; Burd et al., 2009; Campbell, 2000), and can be easily measured (Pan and Price, 2002).

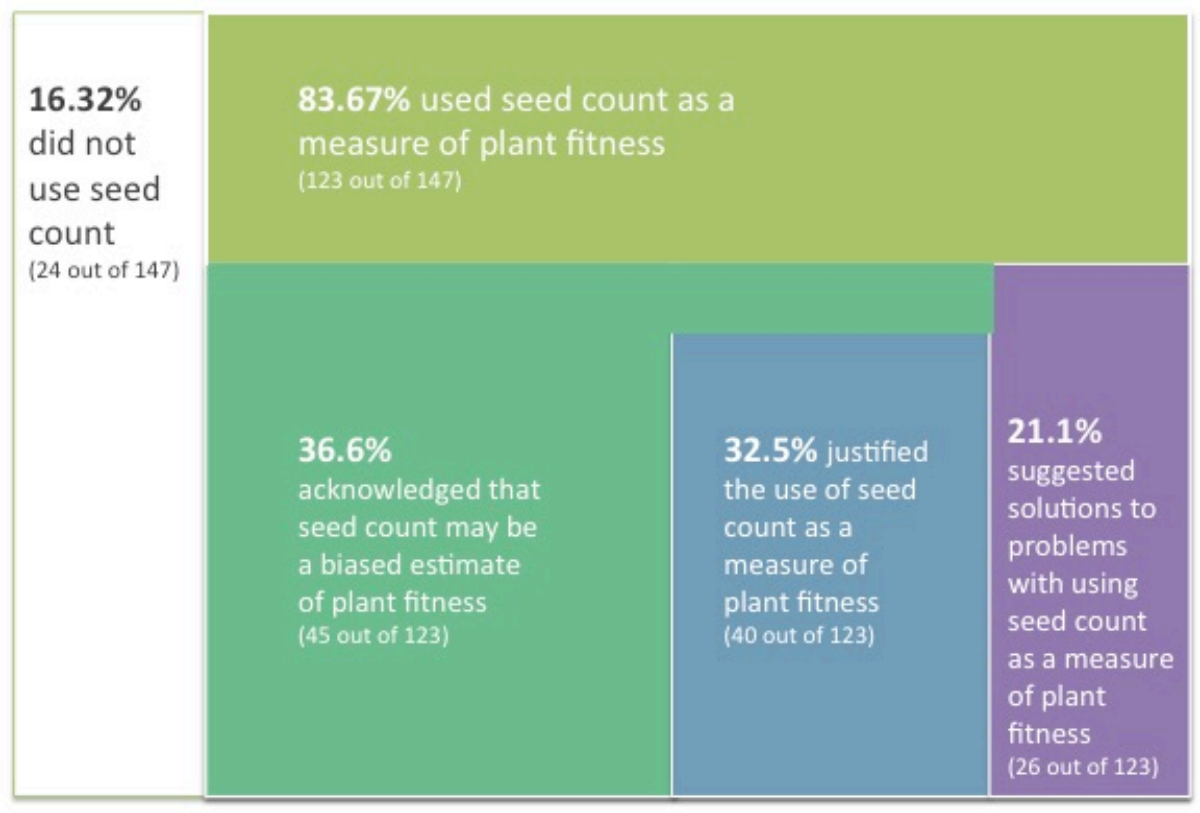

Figure 1.1 An area graph showing the number of studies that have used seed number as a measure of plant fitness, the number of studies that have acknowledged that seed number may be a biased estimate of plant fitness, the number of studies that have justified seed number as a measure of 
fitness, and the number of studies that have suggested solutions to problems with using seed count as a measure of plant fitness. The categories "acknowledged seed count as a biased estimate of fitness", "justified the use of seed count as a measure of fitness", and "suggested solutions to problems with using seed count as a measure of fitness" are nested within the fraction of studies that have used seed count as a measure of fitness.

All studies were first categorized in terms of their recognition of potential issues in relating seed count to fitness (Appendix A). Among the studies that used seed number as a measure of fitness, 45 studies acknowledged that seed count may be a biased estimate of fitness, 40 studies justified its use as a measure of fitness, and only 26 studies have suggested practical solutions or alternatives to using seed number as a measure of fitness (Figure 1.1). It is important to note that $47 \%$ of studies do include an alternative measure of fitness alongside seed count, which suggests that the problem is recognized, even if not explicitly mentioned in the paper (Figure 1.4). Nonetheless, seed count is by far the single most used metric, and papers that acknowledge that seed number may be a biased estimate of fitness are in the minority in the literature.

These recognition categories are not completely hierarchical; some studies that have justified the use of seed count as an appropriate measure of fitness have not acknowledged that seed number may be a biased estimate of fitness. I emphasize that papers falling into the category "acknowledged seed number as a biased measure of fitness" have discussed that seed number may not be an appropriate measure, but have not explicitly tested this. I will provide an overview of the basic distribution of all studies 
among the eight scenarios before going on to examine where these studies fall among these categories of level of recognition of the seed count issue.

\subsubsection{Distribution of studies among scenarios}

I found that $16.3 \%$ of studies could be classified under more than one scenario. In particular, I found that the scenarios of male and female fitness, variation in phenology and trade-offs between allocation to reproduction and defense against herbivory overlapped with other scenarios (Figure 1.2). For example, one study investigated pollinator-mediated selection on flowering phenology and floral traits through female function, and also examined how herbivores affected the relationship between floral traits and female fitness (Chen et al., 2017). Because herbivory can affect female fitness through direct effects on floral traits, this study may fall under two scenarios: variation in phenology, and trade-offs between allocation to reproduction and defense against herbivory. Moreover, Ehrlen (2015) provides a path analysis showing positive and negative associations between flowering date (variation in phenology), pollination activity (male and female success), and herbivory. This path analysis shows that variation in flowering time can affect interactions of pollinators and herbivores with fitness; pollinators can have a positive effect on seed production, while herbivores have negative effects. A trade-off may also occur between seed production and the probability of flowering. Thus, direct effects of flowering time and indirect effects of pollinators and herbivores can influence fitness as measured through seed count. 


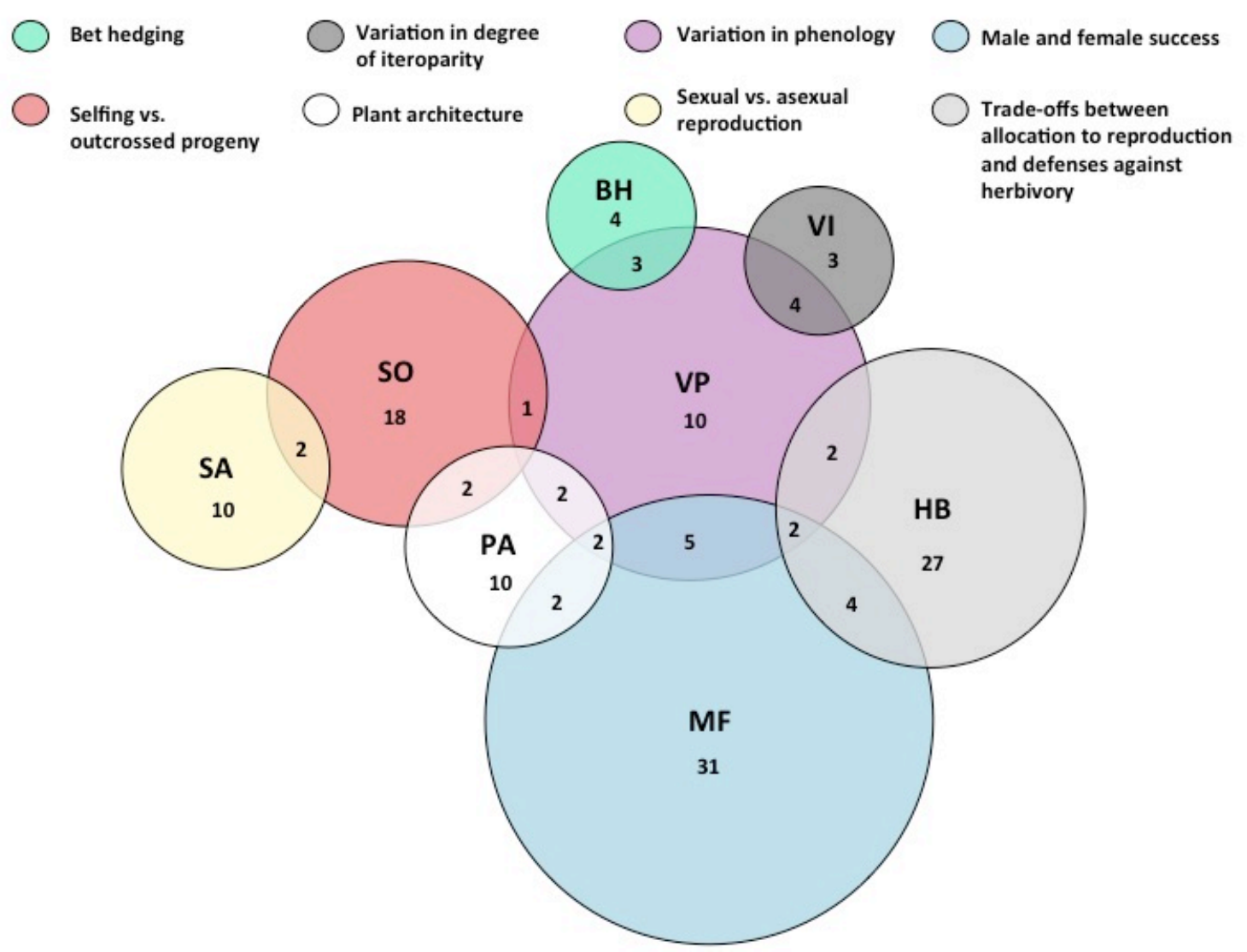

Figure 1. 2 A Venn diagram showing the overlap between the different "scenarios" (see text). The size of each circle represents the number of studies in each scenario. Scenarios: $P A=$ plant architecture, $\mathrm{HB}=$ trade-offs between defense against herbivory and seed number, $\mathrm{MF}=$ male and female fitness, $\mathrm{SO}=$ selfed vs. outcrossed progeny, $\mathrm{SA}=$ sexual vs. asexual reproduction, $\mathrm{VP}=$ variation in phenology, $\mathrm{VI}=$ variation in degree of iteroparity, $\mathrm{BH}=$ bet hedging.

Of the 147 total studies reviewed, the highest proportion of studies that have used seed count as a measure of fitness fall under the scenarios of male and female success, variation in phenology, and the trade-off between allocation to reproduction and defense against herbivory (Figure 1.3). In contrast, relatively few studies that used seed number to measure plant fitness fall under the scenarios of sexual vs. asexual reproduction, variation in degree of iteroparity, and bet hedging (Figure 1.3). It should be noted that a subset of 
studies examined was classified under scenarios that were not in the eight main scenarios identified. The 'other' category included density-dependent effects, hybridization, maternal effects, and symbiosis. Density-dependent interactions can differentially influence individual fitness due to competition among siblings (Campbell et al., 2017), introgressive hybridization can lead to trait combinations that enhance fecundity, and/or pest resistance (Campbell and Snow, 2007); maternal environmental effects can cause variable offspring fitness due to variation in nutrient availability across generations (Jacobs and Lesmeister, 2012); and the effect of mycorrhizal symbiosis can mediate variable effects on plant reproductive success by altering hormone levels in parental plants (Nuortila et al., 2004).

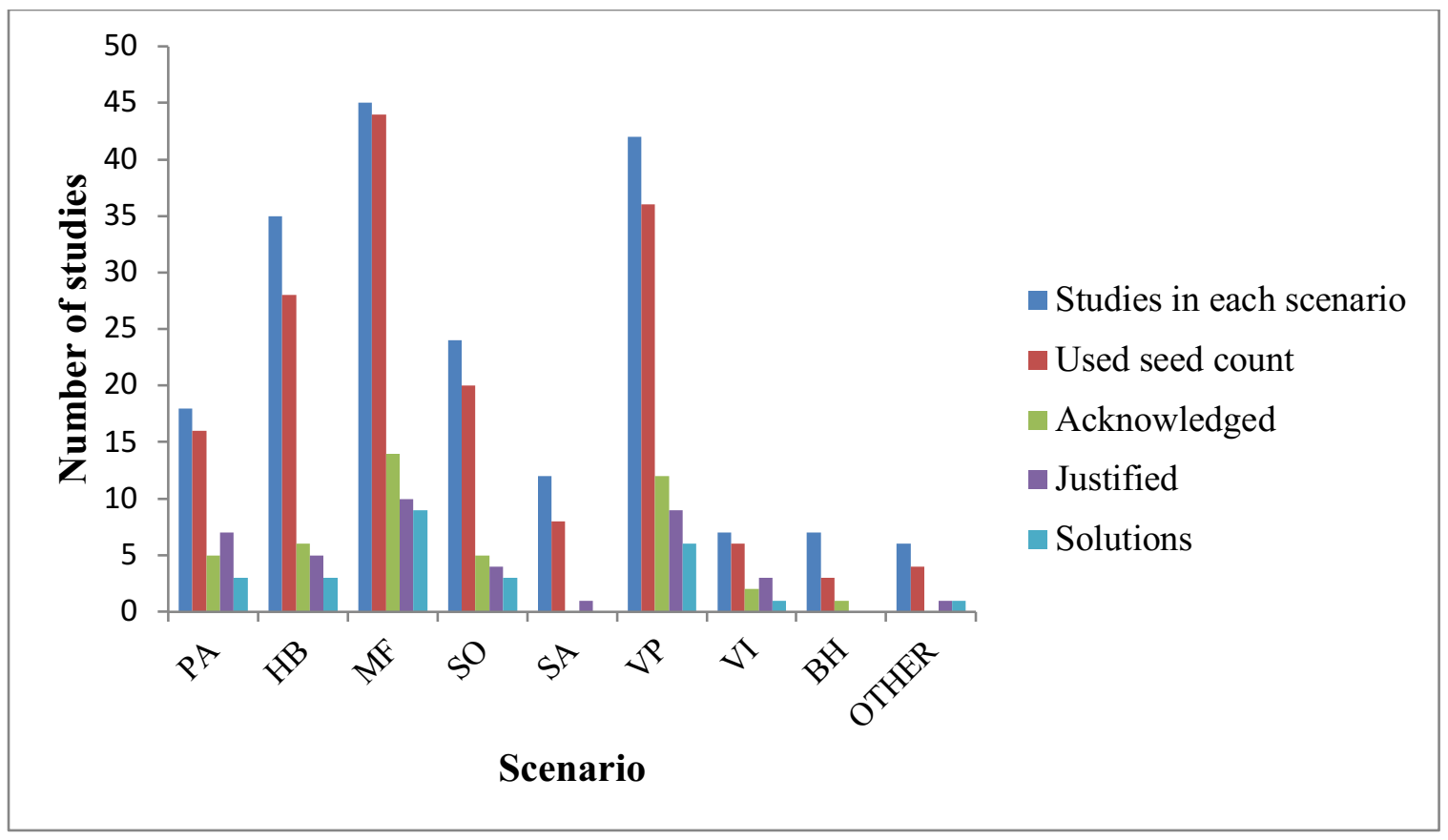

Figure 1.3. Breakdown of reviewed studies into categories of recognition of problems associated with using seed count as a proxy for fitness under each "scenario". The total number of studies that have investigated plant fitness are represented by the dark blue bar, studies that have acknowledged seed count as a biased measure of fitness in red, studies that have justified seed number as a measure of 
fitness in green, studies that have suggested solutions in purple, and studies that have suggested solutions in light blue. Some of the 147 studies examined fall under multiple scenarios, and each occurrence is included in this analysis; therefore, the total number of studies exceeds 147. See Figure 1.2 for scenario abbreviations.

From the fraction of studies that use seed number as a measure of fitness, the largest number of studies that acknowledged that seed number may be a biased estimate of fitness were found under the scenarios of male and female fitness, variation in phenology, and a trade-off between defense against herbivory and seed number (Figure 1.3). The lowest number of studies that have acknowledged seed number as a biased estimate of fitness was found under the scenarios of variation in degree of iteroparity, and bet-hedging. Notably, no studies under the scenario sexual vs. asexual reproduction explicitly acknowledged that seed number might be a biased estimate of fitness (Figure $1.3)$.

The highest proportion of studies that justified the use of seed number as an estimate of fitness were found under the scenarios of male and female fitness, variation in phenology, and plant architecture. In contrast, few studies that justified the use of seed number as an estimate of fitness were found under the scenarios of variation in degree of iteroparity, sexual and asexual reproduction, and bet-hedging (Figure 1.3). Similarly, most studies that have suggested solutions to problems of using seed count as a measure of fitness were under the scenarios of male and female fitness, and variation in phenology. No studies under the scenarios of sexual vs. asexual reproduction and bethedging suggested solutions. 


\subsubsection{Alternative metrics used}

Of the 147 experimental studies reviewed, $53 \%$ of studies exclusively used seed number as a measure of fitness, and $47 \%$ of all studies used an alternative metric of fitness with or instead of seed number (Figure 1.4).

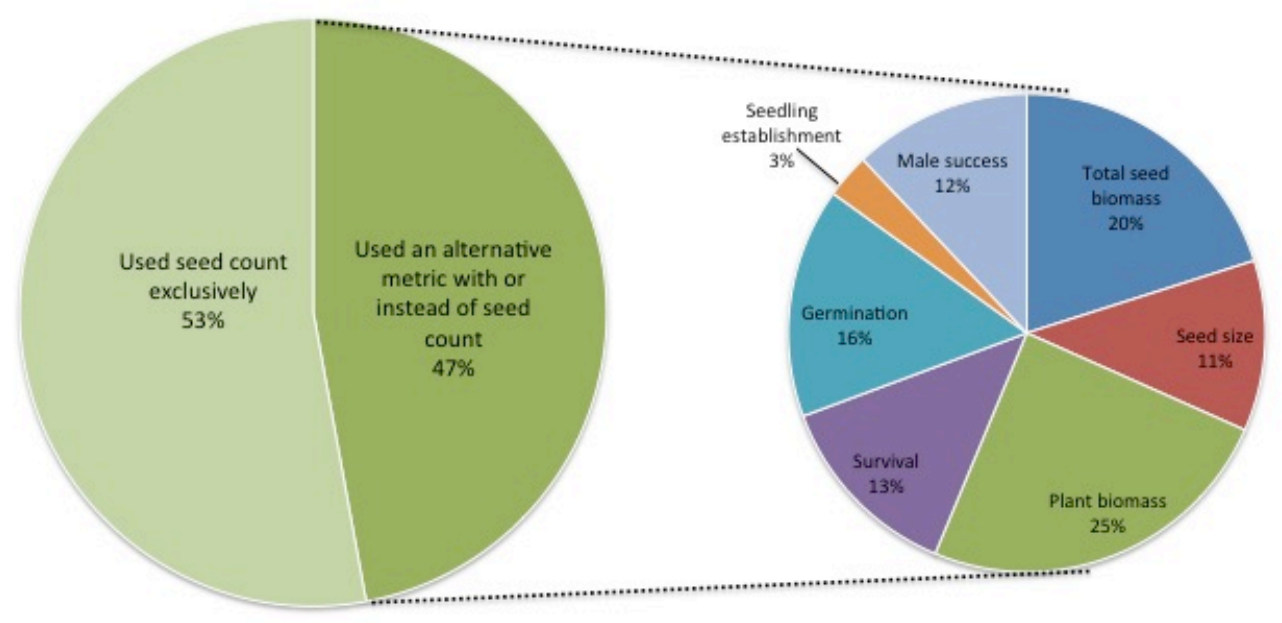

Figure 1.4 Pie charts showing the percentage of all studies that have exclusively used seed number as a measure of fitness and the percentage of studies that have used an alternative measure of fitness with or instead of seed count. The second pie chart represents the percentage of various alternative fitness metrics used in studies that have used an alternative metric with or instead of seed count. 
Out of the seven alternative metrics used in studies investigating plant fitness, most studies used growth-related metrics (plant biomass), and seed-related metrics (seed size, seed biomass). Particular alternative metrics were preferentially used under the different scenarios. Plant biomass was the most-used metric under the scenarios of plant architecture, herbivory, sexual vs. asexual reproduction, variation in phenology, and variation in degree of iteroparity; total seed biomass was the most-used metric under the scenarios of male and female success and selfing vs. outcrossed progeny; and germination success was the most-used metric under the scenario of bet hedging in comparison to other metrics (Figure 1.5). Not surprisingly, measures of male success were also strongly represented in the scenario male and female fitness. 


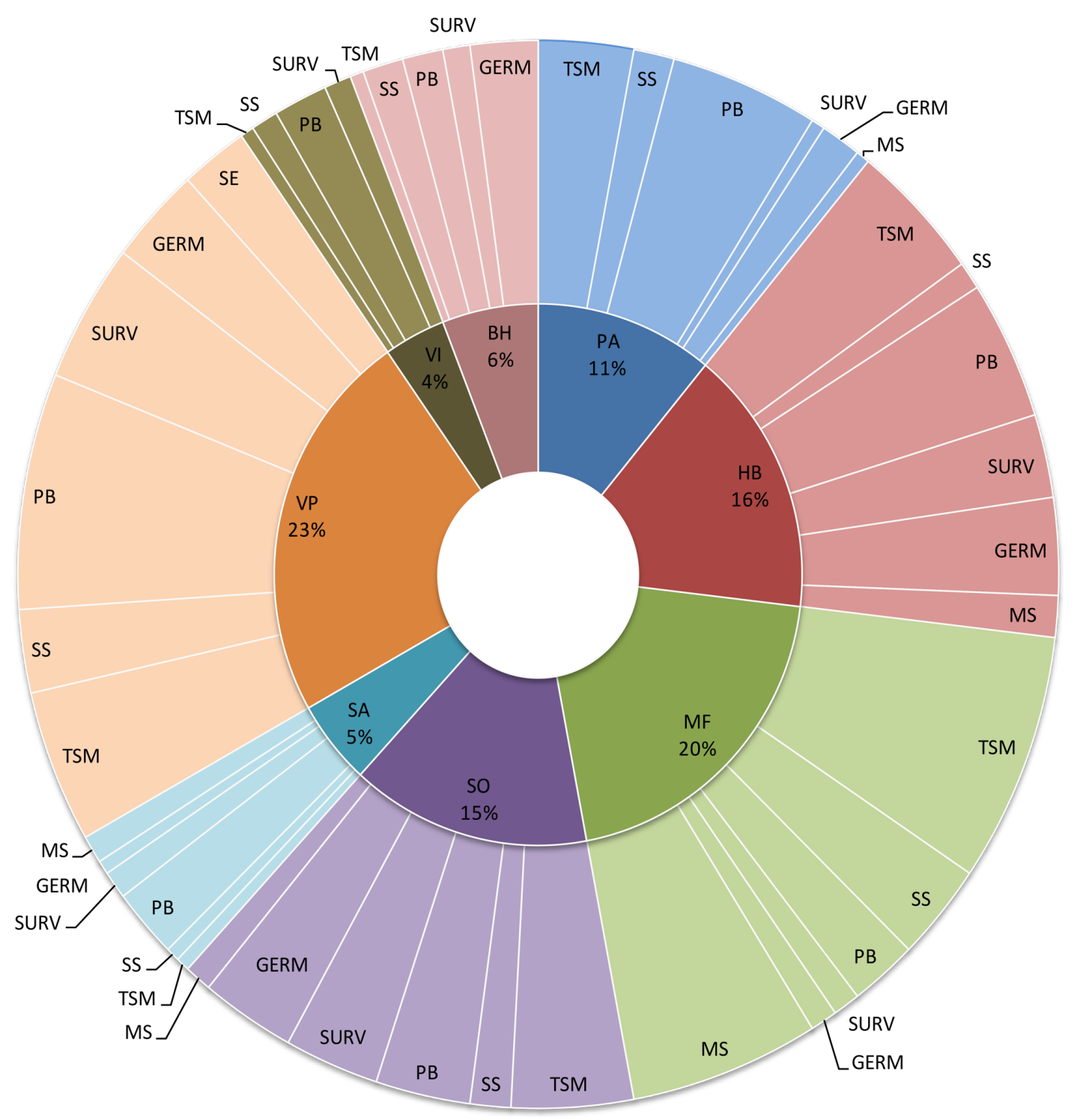

Figure 1.5 Sunburst chart showing the proportions of alternative fitness metrics to seed count used under each scenario (see Fig. 1.2 for scenario abbreviations). The abbreviations for the alternative fitness metrics are: $\mathrm{PB}=$ plant biomass, $\mathrm{SS}=$ seed size, $\mathrm{TSM}=$ total seed biomass, $\mathrm{GERM}=$ germination success, $\mathrm{SURV}=$ survival, $\mathrm{SE}=$ seedling establishment, and MS= male success.

Seed size (diameter and mass) is a key life-history trait and is closely linked to fitness; larger seeds have a higher chance of success (Smith and Fretwell, 1974; Giles, 1990). However there are situations where there is a resource trade-off between seed size and 
seed number; larger seeds are often more successful than smaller seeds, but smaller seeds are more numerous and are therefore likely to have higher dispersal rates (Eriksson, 1999; Smith and Fretwell, 1974). There is supporting evidence that seed sizes are negatively correlated with fecundity, and in some situations smaller seeds may be favoured over larger ones (Simons, 2007). In order to appropriately quantify overall individual fitness, seed size should be considered in conjunction with seed number.

Measurements of plant size or biomass are commonly used as surrogates for fitness and often display positive correlations to fitness as seed count: larger plants generally have more reproductive output, leading to a greater likelihood of leaving viable offspring (Aarssen and Taylor; 1992; Lortie and Aarssen, 1999; Aarssen and Jordan, 2001). Allocation to below-ground biomass can serve as a conservative bet-hedging strategy under unpredictable environmental conditions (e.g. drought, herbivory) (Childs et al., 2010), and is the basis for considering iteroparity itself to be a bet-hedging trait. Additionally, for perennials that may live long and reproduce clonally, plant growth may represent an appropriate measure of fitness if used alongside seed production, especially when there are trade-offs between allocation to growth and reproduction. Thus, the use of growth or biomass as fitness proxies may be appropriate for predominantly clonal species (Hereford, 2009), but seed number should also be considered for plants with mainly sexual strategies. It is currently not known whether the existence of trade offs between asexual and sexual reproduction is general, or whether positive phenotypic correlations generally exist. Further research on this topic is necessary to address whether seed count is an adequate fitness proxy. 
The use of male fitness was well represented in the scenario "male and female success"; however, it was under-represented in other scenarios. This result was expected, as it is notoriously difficult to conduct paternity analyses in the field (Bernasconi, 2003). Regardless, the male contribution may be essential to the accurate estimate of individual total fitness, and this is a problem because studies do not tend to evaluate male and female fitness.

I found that seedling establishment and germination success are among the least frequently used metrics across the eight investigated scenarios (Figure 1.5). This result is surprising in that offspring number adjusted for viability is the most direct route to estimating realized fitness through sexual reproduction, but not surprising in that it requires the effort to produce at least a partial additional generation to complete a study. Seedling establishment and successful germination have previously been recognized as critical to fitness estimation (Ackerman et al., 1996). An example of a scenario under which this might be particularly important is in mixed mating systems where selfing may result in a large number of offspring, but these offspring may be of reduced viability relative to outcrossed offspring depending on the severity of inbreeding depression (Baker et al., 1994; Berg; 1999; Angeloni et al., 2011). Thus, seedling establishment and germination success should be considered along with seed number when measuring plant fitness. 
Selection acting on traits can vary in intensity and direction, and the use of any single measure of fitness can lead to a misleading interpretation of overall fitness (McGraw and Caswell, 1996; Rausher, 1992). Of the studies that used an alternative fitness metric along with seed number, three in particular revealed a disparity between these fitness measures (Metsare et al., 2015; Bigio et al., 2017; Campbell et al., 2017). These three studies fall under the scenarios of density-dependent interactions, variation in phenology, and selfing vs. outcrossed progeny, respectively. Because there were not sufficient data to do a formal quantitative analysis of disparity among fitness measures, I give an overview of the studies and discuss the differences in fitness found when using seed number versus an alternative metric. Thus, these three studies serve as circumstantial evidence that seed number does not align with alternative metrics, and that alternatives are needed to accurately quantify plant fitness.

\subsubsection{Case studies}

\section{Case study \#1: Do different measures of maternal fitness affect estimation of natural selection on floral traits? A lesson from Linum pubescens (Linaceae) (Bigio et al., 2017)}

Selection on floral traits is largely influenced by pollinator behaviour, leading to differential fitness (Chen et al., 2017). Investigating pollinator-mediated selection on floral traits with just one fitness measure may not be appropriate because different pollinator behaviour may have different effects among various fitness measures. For 
instance, variation in floral colour or size can affect pollinator visitation rate, which can create fitness differences among individuals. Bigio et al. (2017) compared the relative roles of multiple fitness measures (fruit set, number of fruits, number of seeds, and seed mass) for estimating pollinator-mediated selection on floral colour and flower diameter in Linum pubescens. Their goal was to identify the most appropriate measure of fitness to accurately assess selection on floral traits.

They found that using different maternal fitness measures produced inconsistent results in determining selection on the two floral traits of $L$. pubescens. First, seed mass was a positive indicator of selection for the colour combination of floral tube throat and stamen colour; however, floral diameter was under positive directional selection when using seed number or fruit number as a measure of fitness. Their results suggest that using multiple fitness measures can accurately estimate selection on floral traits, but the exclusive use of seed number or fruit number would misrepresent selection on flower colour. Thus, using several fitness measures should be taken when investigating mechanisms underlying pollinator-mediated selection on floral traits.

\section{Case study \#2: Four seed-quality measures in orchids with different pollination systems (Metsare et al., 2015)}

In this study, Metsare et al. (2015) used four metrics (seed number, seed abortion, seed viability by tetrazolium test and germination in vitro) to assess seed viability in one or more species simultaneously. The focus of their study was to evaluate differences in seed quality metrics across two different orchid species (one nectar rewarding, one 
deceptive) with two pollination systems (cross-pollination vs. self-pollination). Evidence has shown that there are differences in fruit set and inbreeding depression between rewarding (flowers that contain nectar) and deceptive species (flowers that do not contain nectar); outcrossing individuals produce better quality seeds compared to geitonogamous individuals (Johnsson and Nilsson 1999). Here, they use three treatments to assess how different quality measures reveal actual seed quality. The three treatments performed were: (1) cross-pollination, (2) geitonogamous self-pollination and, (3) natural pollination as a control.

Interestingly, they found that in the rewarding species Platanthera clorantha, seed number, viability, and germination tests suggests higher fitness for outcrossing fruits (higher seed number, viability, and germination), but this trend was only true for the deceptive Orchis militaris when exclusively using seed number as a measure of fitness. Although naturally pollinated $O$. militaris seeds had a relatively higher seed count, their seeds had the lowest germination out of all three treatments. Moreover, seed number did not correlate with seed viability or germination in either species, suggesting that more than one uncorrelated fitness measure should be used when investigating fitness in plants with mixed mating systems. Thus, their results show that only using seed production as a fitness measure can be misleading because important fitness-affecting factors may be ignored without germination or viability tests.

\section{Case study \#3: Is plant fitness proportional to seed set? An experiment and spatial model (Campbell et al., 2017)}


Most empirical studies have used a component of individual fitness such as fecundity to estimate overall fitness. However, using fecundity may be biased if densitydependent interactions between siblings affect survival and reproduction of offspring from high- and low-fecundity parents differently. Moreover, there are mechanisms that can differentially influence individual fitness during transitions between life cycles. Campbell et al. (2017) proposed that a high production of seeds does not translate into high seedling survival to reproduction. Specifically, they focused on how spatial distribution of offspring and effects of sibling interactions can differentially influence individual fitness during the gap between seed input and seedling emergence. Using seeds of a wildflower Ipomopsis aggregata, they mimicked natural seed dispersal, with areas of overlapping seed shadows and used genetic markers to track offspring in order to test for differences in offspring success. Spatial models revealed that relative fitness is modified by sibling interactions taking place between seed dispersal and juvenile recruitment.

Their results revealed that post-dispersal density dependent interactions caused differences in plant fecundity among individuals. As well, individual differences in fecundity arose from sibling competition, which depended on seed dispersal. It was found that high-fecundity parents that produced twice as many seeds as low-fecundity parents produced fewer than twice the number of successful seedlings. Therefore, a trade-off between high seed production and offspring survival suggests that competition among siblings due to density-dependent interactions can result in lower survivability of seeds. 
In this situation, measuring relative fitness based solely on seed number would not be accurate and should be supplemented with survivability of seeds.

\subsection{Conclusion}

In conclusion, seed count is widely used as a measure of fitness despite a lack of information on its reliability. While a small percentage of studies have recognized the problems that may arise with using seed number as a measure of fitness, a majority of studies have not addressed the consequences associated with the exclusive use of seed number as a measure of fitness. We acknowledge that there are situations in which seed number may be the most appropriate measure of fitness, but the notion that seed number is a reliable estimate of fitness is unclear for many scenarios in nature.

This literature review aimed first to help recognize or identify the specific situations in which there are confounding effects in the relationship between seed number and fitness. It is of course important that investigators be aware of the consequences of using seed number as a measure of fitness when conducting experimental or field studies, and appropriate fitness metrics are expected to vary among scenarios and study species. We note that there may be other scenarios that have not been mentioned in this review, but the discussions outlined here are meant to provide fruitful avenues for future research. While this review is not an exhaustive study, results suggest particular situations under which the exclusive use of seed number may either under- or over-estimate fitness, and that it is important to obtain alternative measures of fitness, especially when large 
discrepancies are expected. We therefore emphasize a need for data reporting on more than one fitness measure within individual studies; this would allow a meta-analysis suggesting appropriate fitness measures for different scenarios.

Ideally, then, plant fitness measurement would include a combination of seed number with an alternative metric. This could include measuring fitness components over multiple stages of the individual's life cycle (i.e. vegetative, reproduction, and survival). It is hoped that this review cautions researchers to be mindful of the potential bias in the exclusive use of seed count as a measure of fitness, and to encourage the use of multiple measures of fitness when feasible. 


\section{Chapter 2: Variable constraints disrupt the relationship between seed}

count and fitness

(Sections 2.1-2.5 is in manuscript format and is being prepared for publication as: Wen L. and Simons A.M 'Delusions of grandeur: seed count is not fitness under variable environments')

\subsection{Introduction}

The concept of fitness is central to evolutionary biology--yet difficult to define-and often described in terms of the number of descendants produced. For example, fitness can be conceptualized as the realized values of an individual's fitness components (i.e. survival of offspring) (de Jong, 1994; McGraw and Caswell, 1996). Our ability to measure fitness is thus important for addressing key questions about life history evolution (Endler, 1986; Stearns, 1992; Roff, 2002), and about adaptation in general (Dobzhansky, 1968; Williams, 1966; Sober, 1984; de Jong, 1994). However, direct measures of fitness can be difficult to obtain. Therefore, empiricists often use fitness proxies that are assumed to be associated with total fitness (Roff, 1992). Assumptions underlying the association between fitness and proxies of fitness are often not tested, and their reliability as estimates of fitness is generally unknown (Thoday, 1953; Lande and Arnold, 1983; Mousseau and Roff, 1987; Charnov, 1997).

The majority of plant evolutionary ecological studies use seed number as a measure of fitness (see Chapter 1, p. 4). There are good reasons for this: seed number is 
generally easily obtained either through direct count, or through estimation based on fruit count. Furthermore, seeds are often the most recognizable structure that transfers genetic material across generations, and disperse from the parent plant (Pan and Price, 2002). However, the relationship between true fitness and seed count may be weakened or "disrupted" under several natural scenarios: For example, some plant species can propagate both asexually — e.g. vegetative propagation, budding — and sexually (Pan and Price, 2002), thus, seed count would provide a biased estimate of fitness when individuals invest differently in asexual and sexual reproduction; plant architecture may influence fitness through factors such as dispersal or pollination success ( $\mathrm{O}^{\prime}$ Connell and Johnston, 1998); success as a male parent is not reflected in an individual's seed count when plants outcross (Devlin, 1989); trade-offs between allocation to reproduction and defenses against herbivory may exist (Agrawal et al., 1999); individuals that allocate more energy to reproduction might suffer lower residual reproductive value (Miller et al., 2012). Moreover, the use of seed count assumes a strong association between the number of seeds produced by an individual and number of successful offspring, yet variation among individuals in self-fertilized and outcrossed seeds may result in fitness variation due to inbreeding depression (Berg and Torstensson, 1999); individuals may have relatively low fitness in some years as a result of a bet-hedging strategy that increases the geometric mean fitness under fluctuating conditions (Simons, 2011); finally, plastic adjustment of seed production observed to result from variation in flowering phenology among individuals may affect seed quality (Galen and Stanton, 1991). Here, we investigate the reliability of seed count as a fitness measure under this final scenario of variable phenology by manipulating seasonal constraints. 
Phenology, or the seasonal timing of life history events and transitions, may have important fitness effects (Zimmerman and Gross, 1984; Rafferty et al., 2013, Weis et al., 2014), especially when timing influences species interactions. For instance, in temperate insects, precise seasonal timing of egg hatch ensures that the larval stage coincides with optimal conditions for feeding, development and growth (Sniegula, 2016), and adjustment of the transition to the adult stage ensures optimal conditions for feeding, reproduction and dispersal (Danks, 2008). Similarly in plants, constraints on flowering phenology can impose fitness costs by causing asynchrony between flowering and pollinating insects (Forrest, 2016), or by influencing the allocation of resources to growth versus reproduction (Austen and Weis, 2015). For example, yearly variation in temperature and precipitation during a flowering season may affect pollinator abundance and activity and lead to variation in plant reproductive success (Asikainen, 2005).

Variation in phenology can also affect fitness independently of species interactions. Environmentally induced differences in germination and development can result in variance in reproductive phenology: in monocarpic plants, the transition from the vegetative to reproductive phase is often marked by the emergence of a reproductive stalk from a basal rosette, termed bolting. The phenology of this transition to reproduction is critical, because semelparous plants must reproduce successfully before the season ends, and selection should act against individuals with incompletely exhausted resources (Simons and Johnston, 2003; Hughes and Simons, 2014c). Previous work on the monocarpic herb, Lobelia inflata, has shown that a semelparous species' pattern of 
reproductive allocation is phenotypically plastic to season length cues (Hughes and Simons, 2014b). Although semelparous organisms can be classified as those that show a single, "big bang" reproductive episode, typical reproduction in semelparous organisms occurs over a prolonged reproductive episode. Thus, parity may be considered a continuum between pure semelparity, and pure iteroparity (Hughes and Simons, 2014a). Specifically, in L.inflata, individuals that bolt later experience a more constrained season length, and show even more extreme semelparity (Hughes and Simons, 2014a): they express reduced time to first reproduction, smaller size at reproduction, and multiplication of reproductive organs through increased branching, (Hughes and Simons, 2014a). Remarkably, individuals experiencing a constrained season seem to compensate and do not suffer the expected reduction in seed number (Hughes and Simons, 2014a). However, in this work, offspring quality was not assessed. A fuller understanding of the effect of phenology on the relationship between seed count and fitness requires an assessment of offspring quality because high seed production may not translate into high reproductive success.

\subsubsection{Model system: Lobelia inflata}

Lobelia inflata makes an excellent model system for the study of effects of phenology on seed count and fitness for several reasons. First, as mentioned above, higher than expected seed production was observed when season length was experimentally shortened (Hughes and Simons, 2014a). Second, L. inflata is semelparous, and lifetime reproductive success can be observed during a single growing 
season in nature. Third, L. inflata has a simple acropetal flowering pattern, where fruits form sequentially along inflorescences, making it possible to track the packaging of reproductive effort through the growing season (Simons and Johnston, 2000a). Fourth, the populations under study are completely self-fertilizing (Hughes et al. 2014); therefore, the effect of mating system on genetic load found in some species can be ruled out as an explanation of fitness differences among siblings (Hughes and Simons, 2015). Finally, total reproductive success can be directly determined because L. inflata reproduces exclusively by seed.

\subsubsection{Goals of study}

In this study, we test the hypothesis that interindividual variation in phenology results in a disruption in the relationship between seed count and fitness, using the monocarpic plant, Lobelia inflata. Specifically, we predict that a constrained season length after bolting results in the production of numerous seeds but of lower quality. Later bolting plants showing a more extreme semelparous ("big bang”) reproductive strategy (Hughes and Simons, 2014a) will trade off seed quality for seed number, thus biasing seed count as a measure of true fitness. In an observational study, later bolting could be correlated with greater resource acquisition prior to bolting, which would affect seed production. However, the manipulation of season lengths only following bolting precludes this possibility in the present study. Manipulated phenology and effective season length was accomplished by inducing bolting in experimental plants, and splitting these plants between a growth-chamber environment that provided cues of a constrained season length (shorter photoperiod, lower temperature), and one that mimicked a long 
season (longer photoperiod, higher temperature). Seed number and quality were then assessed for constrained and unconstrained plants by direct seed and fruit counts, and then by observing germination and seedling success under common conditions. Germination and seedling survival were measured both at the whole-plant level and also as patterns of reproductive allocation and fitness among fruits within individuals to test whether seed quality declines within individuals or is expressed uniformly across sequential fruits, and whether this pattern differs between the constrained and full season. If the expected fitness return on a seed differs depending on effective season length, seed count should be used cautiously if variation in reproductive phenology exists.

\subsection{Materials and methods}

\subsubsection{Lobelia inflata and field collection}

L. inflata (Campanulaceae) is an herbaceous, monocarpic perennial native to North America that grows well in disturbed and sandy areas. Seeds of L. inflata typically germinate in the spring and early summer and form basal rosettes. L. inflata has two distinct phases of life: the vegetative rosette stage in which resources are accumulated, which terminates with the transition to the reproductive stage (expending resources on the production of offspring) upon "bolting", or the formation of a flowering stalk in the first or second season (Hughes an Simons, 2014c). Reproduction occurs in an acropetal pattern (i.e. from basal to distal positions) along the stalk, with most plants producing between 10-100 fruits, and many thousands of seeds, over the course of the reproductive 
season (Hughes and Simons, 2014b). Bolting is triggered by light intensity and photoperiod (daylength), is irreversible, and has to meet a threshold for rosette size that changes with time of year (Simons and Johnston, 2003). Late bolting decreases the time available for a plant to reproduce, leading to potential fitness consequences. If the plant does not enter the reproductive stage during the first year, the rosette is capable of overwintering (Simons and Johnston, 2000b). Upon fruit maturation (the browning of fruits), seeds are passively dispersed and the plant senesces.

Individuals are exclusively self-fertilizing, resulting in complete homozygosity after a few generations (Hughes \& Simons, 2015). A closed tube of fused anthers ensures self-fertilization; pollen is released directly onto the stigma of the same flower. Aside from enforcing self-fertilization, the anther tube also prevents outcrossing by acting as a mechanical barrier to pollen release. Offspring have been assumed to be genetically identical to the parent, with populations consisting of independent genetic lineages (Simons and Johnston, 2000b). Recent research using nuclear microsatellite markers developed for genotyping reproductive lineages of $L$. inflata, supports this assumption (Hughes et al. 2015; Hughes \& Simons, 2015), with no observations of outcrossing or heterozygosity in the populations studied.

Mature fruits of $L$. inflata were collected during the autumn of 2016 from natural populations in Gatineau Park, Gatineau, Quebec (Lat. $45^{\circ} 29^{\prime}$ N, Long. $75^{\circ} 50^{\prime} \mathrm{W}$ ). Seeds from ten field-collected individuals separated by an average distance of $6.6 \mathrm{~m}$ and minimum distance of $2 \mathrm{~m}$ were used to found experimental populations. Here we are 
principally interested in the expression of fitness in contrasting environments, and thus focus on within- rather than among-individual fitness expression patterns.

\subsubsection{Season length manipulation}

To produce offspring plants, 100 seeds from each lineage were placed in 10 replicate petri dishes $(60 \times 15 \mathrm{~mm}$ Fisherbrand) lined with moistened $5.5 \mathrm{~cm}$ doubled filter paper for up to 14 days. Seeds were cold stratified for 14 days in darkness at $5^{\circ} \mathrm{C}$. Seeds were then placed in Biochambers SG-30 seed germinators set to a 12h/12h day/night light regimen at $20^{\circ} \mathrm{C}$ with $80 \%$ humidity until germination.

Upon germination, seedlings of different lineages were planted at randomized positions in cells $(4 \mathrm{~cm} \times 4 \mathrm{~cm})$ of 32-celled trays with autoclaved soil (Promix 860B). Trays were then transferred to a Biochambers AC- 40 growth chamber set to a $16 \mathrm{~h} / 8 \mathrm{~h}$ day/night photoperiod schedule at $24^{\circ} \mathrm{C}$ to induce growth and bolting. Trays were watered every 3-4 days, and a 15-5-15 liquid fertilizer mixture was added once every two weeks. Plants that did not bolt within 60 days ( \pm 1 day) were subjected to a 31 day vernalization treatment (induction of flowering by exposure to prolonged cold) at $5^{\circ} \mathrm{C}$ in the dark. All plants that bolted were included in the experiment.

Effective season length variation among individuals in natural populations results from the initiation of bolting over an extended period beginning as early as late May through July, and flower and fruit production typically ends by October (Simons \& 
Johnston, 2003). To study the effect of season length, upon bolting, plants were split equally between two experimental environments: a "long" season representing average summer-like photoperiod and temperature conditions $(16.5 \mathrm{~h} / 7.5$ day/night photoperiod at $24^{\circ} \mathrm{C}$ ) and a "constrained" season representing late-season photoperiod and temperature conditions $\left(12 \mathrm{~h} / 12 \mathrm{~h}\right.$ day/night photoperiod at $\left.20^{\circ} \mathrm{C}\right)$. The two contrasting conditions remained constant through time. Thirty-six bolted individuals were monitored until senescence, which was the termination of flowering, and the observation of browning of all fruits. Full duration of senescence of a plant ranged from 90-100 days. Mature fruits were collected, including all fruits on main stem and branches, if branching occurred.

\subsubsection{Trait assays}

With the aim of characterizing trait expression in the two contrasting manipulated environments, traits at both the whole-plant and within-plant level were assessed for each individual. These included measures of plant size, fruit number and individual fruit sizes, and fruit-specific seed size and number.

Final plant height was measured as the distance from the base of the stalk to tip of the latest fruit for all plants. The final stem diameter was measured $2 \mathrm{~cm}$ from the base of the stalk using a Vernier caliper $( \pm 0.01 \mathrm{~mm})$.

Fruits were counted, and fruit position on main stem was recorded for all plants at senescence. The total number of fruit produced by a plant included all fruits at all 
positions, including on the main stem and branches. The width of each fruit was measured as the diameter using a Vernier caliper $( \pm 0.01 \mathrm{~mm})$. The chronological order of fruit production (starting from the earliest fruit) is noted by position along the main raceme. Since it is difficult to determine the temporal order of fruits on branches from position, only the fruits on the main stem (1096 out of 2673) were used in any analyses that included fruit position effects. Total fruit number ranged from 11 to 150 . Because total fruit number varied among individuals, position was scaled to relative position ( $5^{\mathrm{h}}$, $50^{\text {th }}$, and $95^{\text {th }}$ percentile) for each plant for analyses of reproductive allocation.

Seed number per fruit at the $5^{\text {th }}, 50^{\text {th }}$, and $95^{\text {th }}$ percentile position was determined by manual count under a light microscope. Seed size was measured by: i) collecting thirty seeds from three fruits at the $5^{\text {th }}, 50^{\text {th }}$, and $95^{\text {th }}$ percentile position along the raceme; ii) imbibing seeds on a moistened filter paper-lined petri dish for 24 hours; and iii) measuring seed width using Image J 1.51. Seed counts were taken for a total of 108 fruits over the full fruit size range; thus, a general relationship between seed number and fruit size was obtained by fitting a second-degree polynomial. This equation was then used to estimate the total reproductive output (the number of seeds) per plant, based on measurements of every fruit of all individuals.

Under laboratory conditions, fitness (e.g. germination success, seedling viability) is artificially inflated (St Juliana and Janzen, 2007), and true underlying variance in fitness will not be observed. To introduce variation in seed fitness under laboratory conditions, salinity was used as an abiotic stress (For details, see Appendix B). Salinity is 
known to be one of the major abiotic stresses that affect plant growth. Seed germination and seedling growth are the stages most sensitive to salinity, where germination or survival of seeds is often delayed or prevented (Papastylianou et al., 2017). Thirty coldstratified seeds collected from each fruit position $\left(95^{\text {th }}, 50^{\text {th }}\right.$, and $5^{\text {th }}$ percentile $)$ of the 36 individuals were imbibed in water for $24 \mathrm{~h}$. Seeds were then placed on $6 \times 5 \mathrm{~cm}$ petri dishes on a double layer of filter paper, and watered with a solution of $0.01 \mathrm{M} \mathrm{NaCl}$ and distilled water, and allowed to germinate under a continuous $12 \mathrm{~h} / 12 \mathrm{~h}$ day/night photoperiod at $20^{\circ} \mathrm{C}$ and $80 \%$ humidity in seed germinators. Seeds of a subsample of six of the 36 individual plants were individually 'tracked' (recorded seed size) at each of the three fruit positions for germination and survival in order to determine the effect of seed size on fitness. These seeds were placed individually on labelled hole-punched 'islands' (made from Fisherbrand filter paper). Germination was assessed as the protrusion of the radicle through the testa, and counts were made daily. Time (days) to germination and total germination percentage were recorded. Germination fraction was transformed by taking the arcsine of its square root prior to analysis.

To assess survival, seedlings were transferred to 72-celled trays with autoclaved soil (Promix 860B), and placed in a Biochambers AC-40 growth chamber set to a $16 \mathrm{~h} / 8 \mathrm{~h}$ day/night photoperiod schedule at $24^{\circ} \mathrm{C}$. Seedlings were initially treated with a solution of $0.01 \mathrm{M} \mathrm{NaCl}$ and distilled water, and were then watered with only distilled water. To assess vigour, seedlings were observed daily for survival, and measurements of developing rosettes were taken daily for 5 days, and then every other day for 20 days with a Vernier caliper $( \pm 0.01 \mathrm{~mm})$. To determine viability, non-germinating seeds were 
subjected to a $14 \mathrm{~d}$ cold stratification and a second germination trial. Survival fraction was transformed by taking the arcsine of its square root prior to any statistical analyses.

\subsubsection{Statistical analyses}

Analyses were performed on three levels: general comparisons of trait expression between two environments, patterns of allocation across fruits, and fitness across the two environments. Seven main reproductive traits were investigated: fruit number, fruit size, seed number, seed size, germination fraction, mean germination time, and seedling survival.

Overall trait means in the two environments were first compared using t-tests, simply using environment as the unit of replication. A two-factor ANOVA was then used to model the effect of fruit position and environment on each trait. Tests showing a significant effect of fruit position were followed by Tukey HSD tests to assess which groups differed. Proportional allocation across fruits was obtained by standardizing to a mean fruit size of 1 within each individual. For analyses of proportional allocation across fruits, an ANCOVA was used to model the effect of environment and relative fruit position on standardized fruit size (all fruit sizes standardized within individuals). Patterns of allocation in the two environments were further explored with linear and quadratic regression. 
A two-factor ANOVA was used to model the effect of environment and fruit position on germination fraction, mean germination time, and seedling survival. Tests showing a significant effect of fruit position were followed by Tukey HSD post hoc tests to determine which groups differed.

A mixed effects logistic regression was used with seed size as a nested effect within fruit position to examine fruit positional effects (accounting for seed sizes differences) on germination and survival fractions. All statistical analyses were performed in R 3.4.2.

To estimate the effective fitness of one seed produced in the short environment relative to one produced in the long environment, the mean seed survival was calculated for each individual based on observed germination and survival fractions across fruits weighted by number of observed seeds.

Finally, the total expected fitness for individuals, without considering seedling success (i.e. purely counting seeds), was determined for both environments using the total seed numbers calculated from seed counts and their relationship with fruit measurements. The realized fitness, i.e. taking survival into consideration, was calculated for fruits on the main raceme of individuals in the two environments using the estimated seed numbers from fruit measurements and germination and survival fractions. This measure will be referred to as "realized" or "true fitness" for simplicity. Realized fitness was also 
calculated including all fruits of individuals in the two environments, under the assumption that the fruit size-seed survival relationship holds for fruits on branches.

\subsection{Results}

Overall, plants in the two growth-chamber environments did not differ in height $(P=0.33)$ or stem diameter $(P=0.175)$, but those in the constrained season length environment produced fewer fruit, and larger fruits that each contained more seeds (Table 2.1). Total seed number in main stem fruits per individual — estimated using the observed relationship between fruit size and seed number - differed between the constrained and long-season environments, but total seed number including branch fruits did not differ significantly (Table 2.1). Overall seed sizes did not differ between the long season and constrained season environment (Table 2.1). Fitness, however, is influenced by patterns of reproductive allocation through time (across fruits) and its effects on the relationship between seed quantity and quality.

\subsubsection{Patterns of allocation across fruit}

A two-factor ANOVA shows that fruit size differed between environments and among positions, with no significant interaction effect (Table 2.2). A post-hoc Tukey HSD test reveals that fruits at the most basal position were larger than fruits at the most distal position. 
Because we have individual fruit size data for all main stem fruits, the proportion of reproductive allocation across fruits in the two environments could be investigated further. ANCOVA of standardized fruit size indicates, besides a significant effect of position $(p<0.001)$, a highly significant interaction $(p=0.01)$ between environment and fruit position. Further examination of trends in standardized fruit size across positions in the two environments separately using quadratic regression reveals a highly significant nonlinear decline in fruit size for individuals under a constrained season only (Table 2.3).

Seed number per fruit differed between the two environments and across positions, with a significant interaction effect (Table 2.2). According to a post-hoc Tukey test, seed number is lowest at the distal position (mean=141.2) and highest at the basal position (mean=247.1) with pooled environments as expected; however, the interaction effect is attributable to a significant difference in seed number between the top and other two positions that is expressed in the short chamber only.

Analyses on seed size confirmed no difference between environments as observed in the simple t-test (Table 2.1), but revealed differences across fruit positions and a significant interaction term (Table 2.2). Results using the subsample of individuals in which seeds were individually tracked yielded qualitatively identical results. A follow-up Tukey test suggests that seed size differed significantly between environments only at the distal position. Specifically, seeds were smaller at the distal position in a constrainedseason environment (mean $=0.273$ ), compared to a long-season environment (mean $=0.290$ ). Although these results are suggestive of differing patterns of allocation 
across fruits in the two environments, inferences about fitness through seed production require seed germination and seedling survival analyses.

\subsubsection{Fitness}

Germination fraction differed significantly between the two environments and among fruit positions, with a significant interaction term (Table 2.4). Lower germination fractions were observed in the constrained-season environment, and seeds of fruit at the distal position from a constrained-season environment showed substantially lower germinability $($ mean $=0.580)$ than seeds from a long-season environment $($ mean=0.835). Germination trials following stratification of nongerminating seeds indicate mortality rather than dormancy; 42 of 171 non-germinating seeds germinated following stratification from a long-season environment (24.6\%), whereas only 33 of 355 germinated from the constrained-season environment $(9.3 \%)$.

Mean time to germination did not differ between environments, but differed among fruit positions (Table 2.4). Seeds from the distal position in both environments took longer to germinate than seeds from the intermediate and basal positions. Although seeds in the distal position from the constrained season took on average two days longer to germinate than those from the long environment, the interaction term is marginally non-significant. 
The survival fraction — of those seeds that germinated — differed between environments (long-season environment mean $=0.76$; constrained-season environment mean $=0.61)$ and positions, and the environment-by-position interaction was also highly significant (Table 2.4). Post-hoc Tukey tests (Table 2.5) find that seedling survival from the basal position in the long-season environment does not differ significantly from that in the constrained environment, but is higher than at any other position in either environment. Seedlings produced from the distal position fruit in the constrained-season environment have lower survival than any other position in either environment, and 30\% lower survival than seedlings from the distal position in the long-season environment (Table 2.5).

Mixed effects logistic regressions, to ask to what extent seed size differences account for fruit positional effects on germination and survival fraction, found no independent effect of fruit position beyond the effect of seed size nested within position (Table 2.6).

The true or realized fitness associated with a seed in a constrained-season environment $(0.532 \pm 0.03)$ is significantly less than $(F=10.6, d f=1, p=0.003)$ a seed in a long-season environment $(0.69 \pm 0.03)$, yielding a relative per-seed fitness of $0.774 \pm 0.034$ under constrained conditions.

Using seed numbers - estimated using the empirical relationship between seed counts and main-stem fruit measurements - i.e. purely counting seeds, the total expected 
fitness for individuals in a constrained-season environment is significantly higher than individuals in a long-season environment (Figure 2.1). However, the apparent fitness advantage in the constrained environment based only on seed count disappears when seedling success is included in fitness (Figure 2.1). Total fitness (surviving seeds) including all fruits of individuals in the two environments may be calculated under the assumption that the fruit size-seed survival relationship observed for the main stem also holds for fruits on branches. Again, the greater fitness under constrained conditions based on seed count alone is reversed when seedling success is included; relative fitness in a constrained-season environment is 0.89 of that in a long-season environment.

Table 2.1 General comparison of reproductive trait expression between two manipulated environments observed in Lobelia inflata.

\begin{tabular}{|c|c|c|c|c|c|}
\hline \multirow[b]{2}{*}{ Trait } & \multirow[b]{2}{*}{$d f$} & \multirow[b]{2}{*}{$\begin{array}{c}F \\
\text { Ratio }\end{array}$} & \multirow[b]{2}{*}{$\mathrm{P}$} & \multicolumn{2}{|c|}{$\begin{array}{c}\text { Mean value for } \\
\text { environment }\end{array}$} \\
\hline & & & & Long & Short \\
\hline Fruit number (all) & 1 & 14.23 & 0.0006 & 92.72 & 55.78 \\
\hline Fruit size (mm; main stem) & 1 & 60.42 & $<0.001$ & 0.405 & 0.520 \\
\hline Fruit size $(\mathrm{mm} ;$ all $)$ & 1 & 450.10 & $<0.001$ & 0.359 & 0.462 \\
\hline Seed number/fruit (3 positions) & 1 & 91.04 & $<0.001$ & 119.59 & 291.93 \\
\hline $\begin{array}{l}\text { Total seed number/ individual } \\
\text { (main stem) }\end{array}$ & 1 & 4.70 & 0.0374 & 4349.00 & 5526.33 \\
\hline $\begin{array}{l}\text { Total seed number/individual } \\
\text { (all) }\end{array}$ & 1 & 1.18 & 0.2863 & 10025.00 & 11493.83 \\
\hline Seed size $(\mathrm{mm})$ & 1 & 0.0045 & 0.9464 & 0.2973 & 0.2970 \\
\hline
\end{tabular}

Table 2.2 Sources of variation in reproductive traits (fruit size, seed number, seed size) across three fruit positions (FP) and two environments (ENV).

\begin{tabular}{|c|c|c|c|c|c|}
\hline Trait & Source & $d f$ & $\begin{array}{l}\text { Sum of } \\
\text { squares }\end{array}$ & $F$ & $P$ \\
\hline Fruit size & ENV & 1 & 0.360 & 90.86 & $<0.001$ \\
\hline
\end{tabular}




\begin{tabular}{llcccc}
\hline & FP & 2 & 0.217 & 27.34 & $<0.001$ \\
& FP*ENV & 2 & 0.011 & 1.36 & 0.2618 \\
Seed number & ENV & 1 & 801867.00 & 126.96 & $<0.001$ \\
& FP & 2 & 230852.07 & 18.27 & $<0.001$ \\
& FP*ENV & 2 & 58482.67 & 4.63 & 0.0119 \\
& ENV & 1 & 0.00000199 & 0.01 & 0.9464 \\
& FP & 2 & 0.022 & 56.66 & $<0.001$ \\
& FP*ENV & 2 & 0.004 & 9.81 & 0.0001 \\
\hline
\end{tabular}

Table 2.3 Exploratory quadratic regressions of fruit size allocation (where fruit size is standardized to a mean of 1 for each individual) on relative fruit position for all fruits produced on the main stem.

\begin{tabular}{llcccc}
\hline \multicolumn{1}{c}{ Environment } & \multicolumn{1}{c}{ Term } & Estimate & Std. Error & t Ratio & $P$ \\
\hline Long & Intercept & 1.068 & 0.016 & 66.01 & $<0.001$ \\
season & Relative FP & -0.155 & 0.024 & -6.43 & $<0.001$ \\
& Quadratic term & 0.143 & 0.093 & 1.54 & 0.1253 \\
Constrained & Intercept & 1.093 & 0.019 & 57.52 & $<0.001$ \\
season & Relative FP & -0.057 & 0.028 & -2.04 & 0.0415 \\
& Quadratic term & -0.764 & 0.109 & -7.00 & $<0.001$ \\
\hline
\end{tabular}

Table 2.4 ANOVA results for sources of variation in germination fraction, mean germination time, and survival fraction across positions in the two contrasting growth-chamber environments.

\begin{tabular}{llcccc}
\hline \multicolumn{1}{c}{ Trait } & Source & $d f$ & $\begin{array}{c}\text { Sum of } \\
\text { squares }\end{array}$ & $F$ & $P$ \\
\hline Germination & ENV & 1 & 0.345 & 11.42 & 0.001 \\
fraction & FP & 2 & 1.066 & 17.67 & $<0.001$ \\
& FP*ENV & 2 & 0.306 & 5.07 & 0.008 \\
Mean & ENV & 1 & 3.786 & 0.498 & 0.482 \\
germination & FP & 2 & 345.39 & 22.73 & $<0.001$ \\
time & FP*ENV & 2 & 43.89 & 2.89 & 0.060 \\
& ENV & 1 & 0.586 & 48.00 & $<0.001$ \\
Survival & FP & 2 & 1.15 & 47.76 & $<0.001$ \\
& FP*ENV & 2 & 0.325 & 13.34 & $<0.001$ \\
& & & & & \\
\hline
\end{tabular}


Table 2.5 Post-hoc Tukey test results for differences in means in survival between groups and across positions in the two growth-chamber environments. Letters that are not shared indicate significant different mean values.

\begin{tabular}{|c|c|c|c|c|}
\hline $\begin{array}{c}\text { Level } \\
(\mathrm{ENV}: \mathrm{FP})\end{array}$ & \multicolumn{3}{|c|}{$\begin{array}{l}\text { Letters showing homogenous } \\
\text { subsets }\end{array}$} & Least sq. Mean \\
\hline Long: Bottom & $\mathrm{A}$ & & & 0.843 \\
\hline Short: Bottom & A & B & & 0.795 \\
\hline Long: Top & & B & $\mathrm{C}$ & 0.717 \\
\hline Long: Middle & & B & $\mathrm{C}$ & 0.712 \\
\hline Short: Middle & & & $\mathrm{C}$ & 0.618 \\
\hline Short: Top & & & $\mathrm{D}$ & 0.416 \\
\hline
\end{tabular}

Table 2.6 Sources of variation in germination and survival fraction as an effect of seed size nested within fruit position in the two environments. Results of a mixed effects logistic regression using the subset of seeds individually tracked for survival, germination and size.

\begin{tabular}{clccc}
\hline \multicolumn{1}{c}{ Trait } & \multicolumn{1}{c}{ Source } & $d f$ & $\begin{array}{c}\text { Wald chi- } \\
\text { square }\end{array}$ & $P$ \\
\hline Germination & ENV & 1 & 43.77 & $<0.001$ \\
& FP & 2 & 0.245 & 0.8846 \\
& FP*ENV & 2 & 45.80 & $<0.001$ \\
& Seed size [FP] & 3 & 198.46 & $<0.001$ \\
Survival & ENV & 1 & 29.66 & $<0.001$ \\
& FP & 2 & 3.50 & 0.1737 \\
& FP*ENV & 2 & 6.32 & 0.0425 \\
& Seed Size [FP] & 3 & 199.24 & $<0.001$ \\
\hline
\end{tabular}


A.

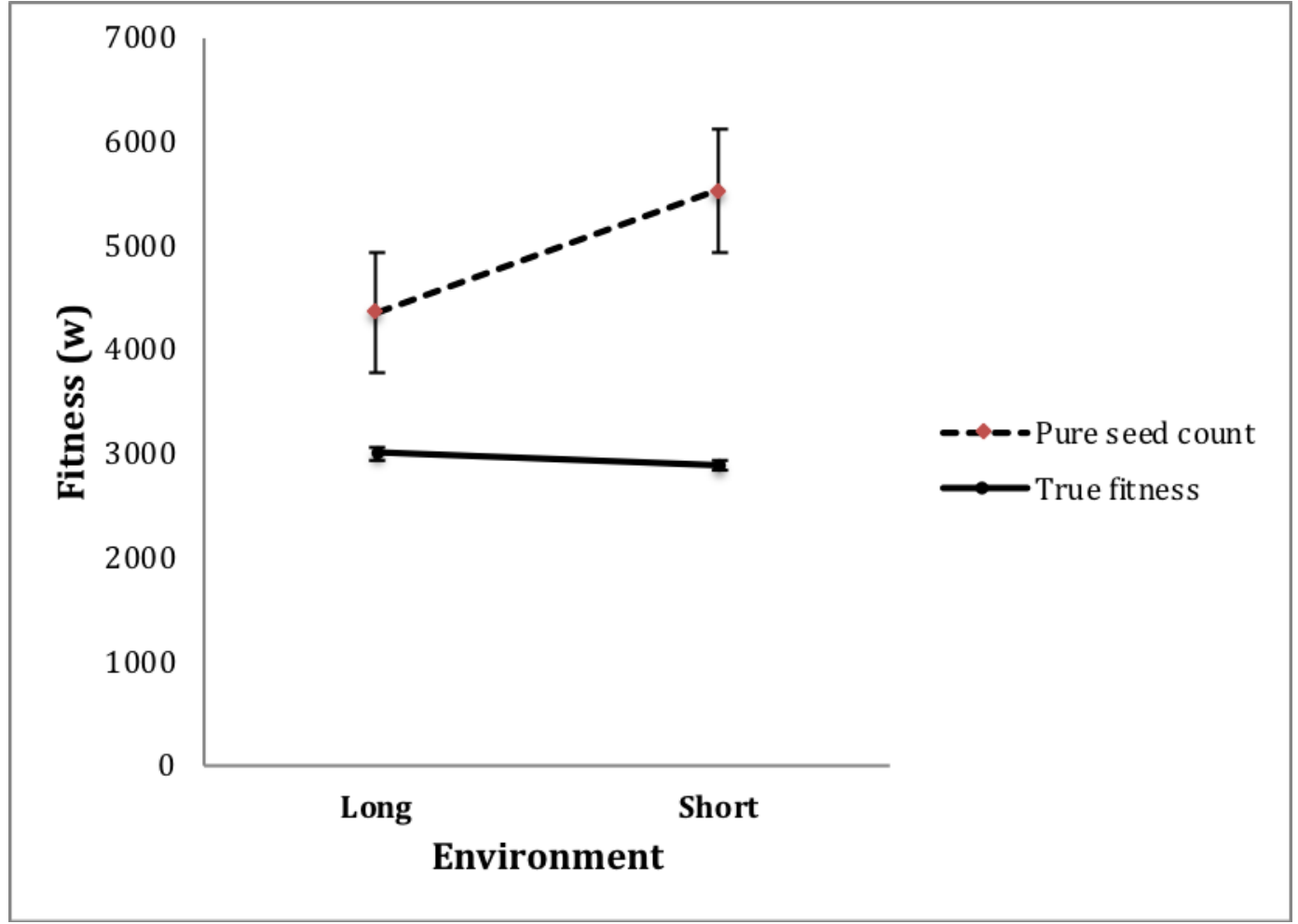

B.

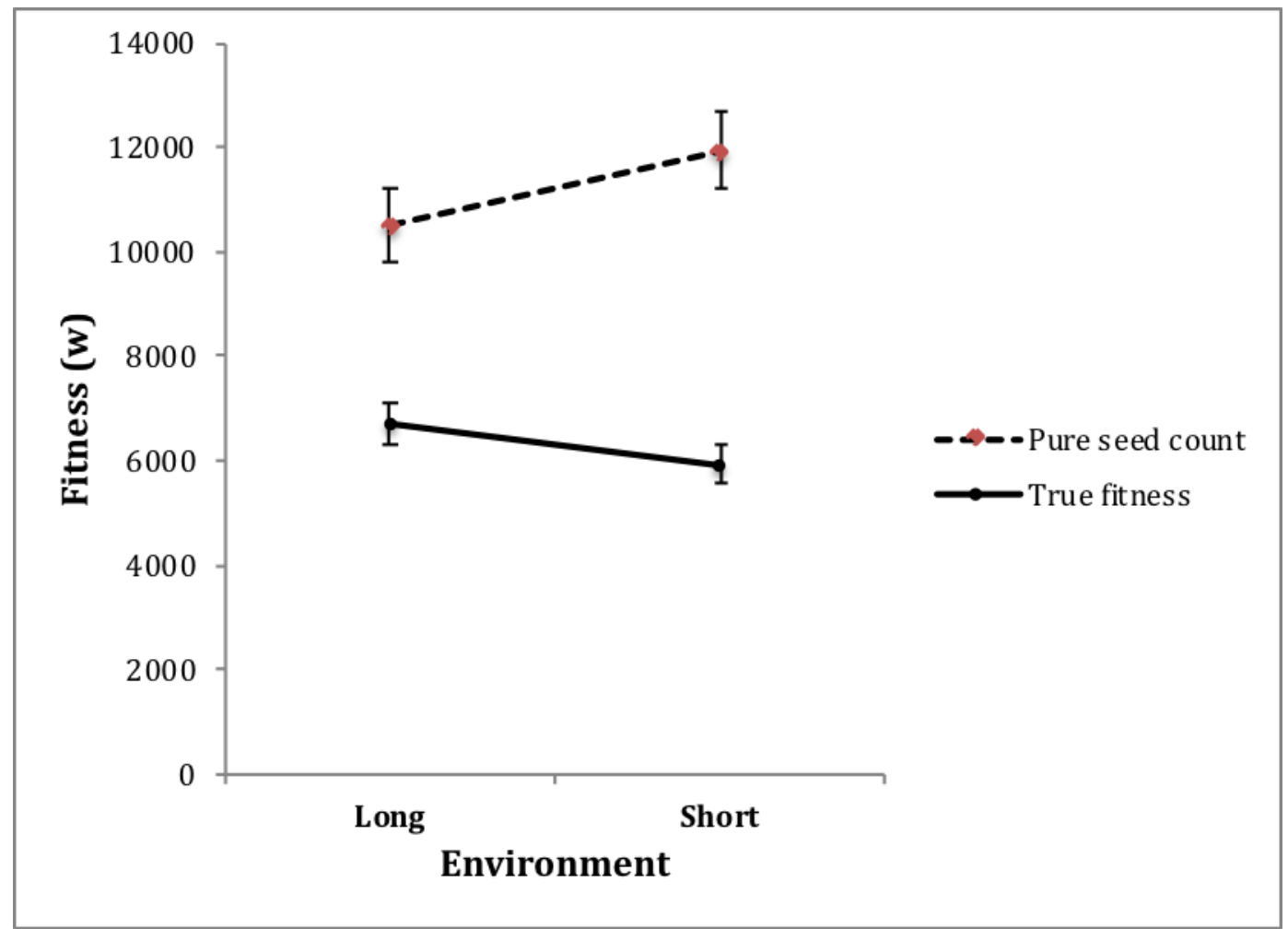


Figure 2.1 Average fitness estimates based on pure seed count and "true fitness" that accounts for successful seed germination and survival, measured across the two manipulated environments. A) Seeds from the main stem fruits, and B) Seeds from all fruits, including fruits from branched stems. Solid lines=true fitness, dashed lines= pure seed count. Error bars represent standard error.

\subsection{Discussion}

Seed number is often used as a measure of fitness. However, it may not accurately represent reproductive success, and may be a biased estimate of fitness under some situations. Previous work found that L. inflata showed plastic responses to variable season lengths in total seed production, implying little to no cost of constrained environments, by exhibiting a more extreme semelparous reproductive strategy (Hughes and Simons, 2014a). However, this study assessed fitness as seed count, and did not test for offspring seedling quality. In the present study, we ask if variable constraints on season length disrupt the relationship between seed number and fitness. Specifically, we test the hypothesis that a constrained season length results in the production of numerous but low quality seeds, thus biasing seed number as a measure of fitness.

The finding that plants under constrained season lengths produce fewer but larger fruit that contained more seeds in total is consistent with Hughes and Simons (2014a) study. However, we found that, although under a constrained season length L. inflata plants produced numerous seeds, they were of lower quality, Total fitness, measured as seed number adjusted for success (germinability and survival), was associated with fruit positional effects and seed size, and importantly, was lower for constrained-season plants. Thus, our findings support our hypothesis, that variable effective season lengths 
experienced by individuals result in deviations in the relationship between seed number and realized fitness. Because we are interested in within-individual fitness expressions, patterns of reproductive allocation among fruits within individuals were further explored.

Patterns of allocation across fruit

Within-individual variation across fruit positions in fruit size, seed number and seed size suggests that fruit position effects play an important role in the regulation of fecundity and reproductive allocation within individuals, which is consistent with work on other species (Nakamura, 1986; Stocklin and Favre, 1994; Lu et al., 2017). For example, seeds produced later in the season, positioned at the distal end, were smaller. Importantly, the effect of fruit position on reproductive traits was environmentdependent, with an exponential decline in fruit size observed only under constrained conditions, and a significant decline in seed size in distal fruits in the constrained season; however, this decline was not reflected in seed number alone. The observed pattern supports the continuum hypothesis; individuals that bolted later (constrained-season plants) showed a more extreme "big-bang" semelparous reproductive strategy. Because plants in a constrained-season environment have less time to allocate energy to reproduction, plants may "rush" reproduction at the end of the season, resulting in high reproductive effort (seed number) that may not result in high realized fitness. 
Fitness- germinability and survival across fruits

Fitness in a constrained vs. in a long-season environment was interpreted in three ways: as the total estimated fitness (purely counting seeds), as total realized fitness (fraction of surviving seedlings, given germination), and as relative per seed fitness. Under the assumption that simple seed count on the main stem represents success, plants in the constrained environment have 1.27 times the fitness of plants in a long season. However, realized parental fitness, estimated as the number of germinating seeds that survived, was no longer significantly higher for constrained season plants: individuals in a constrained-season environment produced many seeds, but both germination success and seedling viability were significantly reduced. This realized fitness reduction under constrained season was due to reduced survival at distal fruit positions.

Seed size differences produced significant effects on germination and survival within fruits; larger seeds had higher germinability and survival than smaller seeds. This result is supported by previous research, where seed size is positively correlated with higher survival and faster early growth under environmental stress (Simons and Johnston, 2000a; Moles, 2004; Metz et al., 2010).

Based only on seed count, apparent fitness was higher (i.e. larger fruits, higher number of seeds) for individuals experiencing a constrained season length. The true or realized fitness in the two environments can be compared as the average relative fitness value of a single seed produced in the constrained season compared to that in a long- 
season environment, which was observed to be $0.774 \pm 0.034$. This shows intriguing evidence in support of the residual reproductive value-dependent hypothesis; in a constrained season length environment, current reproductive value is increased (i.e. by producing numerous seeds) at the expense of decreased residual reproductive value (Hughes and Simons, 2014b).

The apparent fitness advantage under the constrained season disappears after adjusting seed numbers for seedling fitness, suggesting that using seed number alone as a measure of fitness under these circumstances does not reflect true individual fitness. Although an individual under a constrained-season environment produces an average of 11,493 total seeds (or 5,526.33 seeds on its main stem), only 5,930 (or 2,887 on the main stem) contribute to individual reproductive success.

The results are consistent across a random sample of individuals grown in two environments; however, several limitations on inferences from our findings should be noted. First, plants used in this study were reared from seeds that were field-collected, and it is thus possible that the expression of reproductive traits in growth chambers was influenced by maternal environmental effects. However, this is unlikely to generate differences between growth chamber environments, and the observed among- and withinindividual fitness differences were consistent among individuals reared in each environment; furthermore, fitness was measured on seeds that were produced under growth-chamber conditions. Second, because we have only mean seed size in the main dataset and observed variation in germination and survival, we could not distinguish 
between effects of individual seed size, environment, and fruit position. However, our analyses using seeds of a subsample of individual plants that were individually 'tracked' showed that seed size nested within fruit position had a significant effect on germination and survival. Thus, this subsample of individuals with tracked seed sizes corroborates analyses of the individuals with 'untracked' seed sizes, showing that fitness is associated with seed size, which differs across fruit positions. Third, germination and plant growth of $L$. inflata occurred under homogeneous growth chamber conditions that may generate lower variances in reproductive traits compared to under field conditions. However, this would imply that our results are conservative, in that the disparity between seed count and "true" fitness might be higher under field conditions. Finally, the two contrasting environments used in this study meant to mimic short and long seasons are artificial, and it is unknown how the variation generated under these conditions relates to variation in phenology under field conditions. Results of observational field studies would provide insight into the range of phenotypic variation, but interpretation of cause is limited compared to manipulation studies.

\subsection{Conclusion}

In conclusion, our results demonstrate that variation in effective season length results in variation in patterns of reproductive allocation, and this variation disrupts the relationship between seed count and realized fitness using seedling viability. Other studies have shown evidence of plasticity in reproductive traits under varying phenology (Simons and Johnston, 2003; Hughes and Simons, 2014a; Weis et al., 2015), but the fitness effects of this phenological adjustment have been incompletely studied. When 
within-population variation in phenology exists, we conclude that fitness assessment using simple seed count should be interpreted with caution. Future research on phenological variation in the field would increase our understanding of the relationship between seed count and fitness. 


\section{Literature cited}

Aarssen, L. W. and Taylor, D.R. (1992). Fecundity allocation in herbaceous plants. Oikos, 65: 225-232.

Aarssen, L.W and Jordan, C. (2001). Between-species patterns of covariation in plant size, seed size and fecundity in monocarpic herbs. Écoscience, 8:4, 471-477.

Aarssen, L.W (2008) Death without sex - the 'problem of the small' and selection for reproductive economy in flowering plants. Evolutionary Ecology, 22:279-298.

Aarssen, L.W. (2014). Estimating fitness from offspring counts in clonal seed plants. Ideas in Ecology and Evolution, 7:77-83.

Ackerman, J., Sabat, A.M., Zimmerman, J. (1996). Seedling establishment in an epiphytic orchid: An experimental study of seed limitation. Oecologia, 106(2):192-198.

Agrawal, A., Strauss, S., Stout, M. (1999). Costs of induced responses and tolerance to herbivory in male and female fitness components of wild radish. Evolution, 53: 1093- 1104.

Andersson, D.I., Hughes, D. (2010). Antibiotic resistance and its cost: is it possible to reverse resistance? Nature Reviews Microbiology, 8: 260-271. 
Angeloni, F., Ouborg, N.J., Leimu, R. (2011). Meta-analysis on the association of population size and life history with inbreeding depression in plants. Biological Conservation 144: $35-43$.

Antonovics, J, Ellstrand, N.C. (1984). Experimental studies of the evolutionary significance of sexual reproduction. I. A test of the frequency-dependent selection hypothesis. Evolution, 38(1) $103-115$.

Arnold, S. J. and M. J. Wade. (1984). On the measurement of natural and sexual selection: theory. Evolution 38: 709-719.

Asikainen, E., Mutikainen, P. (2005). Pollen and resource limitation in a gynodioecous species. American Journal of Botany, 92(3): 487-494.

Askers, S.E., Jerling L. (1992). Apomixis in plants. Boca Raton and London: CRC Press, pp 298.

Austen, E.J., Weis, A.E. (2015). What drives selection on flowering time? An experimental manipulation of the inherent correlation between genotype and environment. Evolution 69-8: 2018-2033.

Austen, E.J, Weis, A.E. (2016). Estimating selection through male fitness: three complementary methods illuminate the nature and causes of selection on flowering time. Proceedings of the Royal Society B, 283: 20152635. 
Baker, K., Richards, A.J, Tremayne, M. (1994). Fitness constraints on flower number, seed number and seed size in the dimorphic species Primula farinosa and America maritima. New Phytologist, 128(3):563-570.

Barker, J. S. F. (2009). Defining fitness in natural and domesticated populations. In J. Van der Werf, H.-U. Graser, R. Frankham and C. Gondro (Eds.). Adaptation and Fitness in Animal Populations. Springer, Heidelberg, pp. 3-14.

Bawa, K.S, Beach, J.H. (1981). Evolution of sexual systems in flowering plants. Annals of the Missouri Botanical Garden, 68(2):254.

Bazzaz, F. A., Chiariello, N. R., Coley, P. D., and Pitelka, L. F. (1987). Allocating resources to reproduction and defense. BioScience, 37:58-67.

Berg, H., Redbo-Torstensson, P. (1999). Offspring performance in three cleistogamous Viola species. Plant Ecology, 145: 49-58.

Bernasconi, G. (2003). Seed paternity in flowering plants: an evolutionary perspective. Perspectives in Plant Ecology Evolution and Systematics, 6(3):149-158. 
Bigio, L., Lebel, M., Sapir, Y. (2017). Do different measures of maternal fitness affect estimation of natural selection on floral traits? A lesson from Linum pubescens (Linaceae). Journal of Plant Ecology, 10(2) 406-413.

Brommer, J. E. (2000). The evolution of fitness in life-history theory. Biological Reviews, 75: $377-404$.

Burd, M, Ashman, T.L., Campbell. D.R., Dudash, M.R., Johnston, M.O., Knight, T.M., Mazer, S.J., Mitchell, R.J., Steets, J.A., Vamosi, J.C. (2009). Ovule number per flower in a world of unpredictable pollination. American Journal of Botany, 96: 1159-1167.

Campbell, D.R. (2000). Experimental tests of sex-allocation theory in plants. Trends in Ecology \& Evolution, 15: 227-232.

Campbell, L.G. and Snow, A.A. (2007). Competition alters life history and increases the relative fecundity of crop-wild radish hybrids (Raphanus spp.). New Phytologist, 173:648-660.

Campbell, D.R, Brody, A.K, Price, M.V, Waster, N.M, Aldridge, G. (2017). Is plant fitness proportional to seed set? An experiment and a spatial model. The American Naturalist, 190(6).

Charlesworth, D., Willis, J.H. (2009). The genetics of inbreeding depression. Nature reviews, 10:783-796. 
Charnov, E. L. (1997). Trade-off-invariant rules for evolutionary stable life histories. Nature, 387: 393-394.

Chen, L., Zhang, B., Li, Q. (2017). Pollinator-mediated selection on flowering phenology and floral display in a distylous herb Primula alpicola. Scientific Reports, 7:13157

Chevin, L.M. (2011). On measuring selection in experimental evolution. Biology Letters, 7: 210213.

Childs, D.Z, Metcalf, C.J.E, Rees, M. (2010) Evolutionary bet-hedging in the real world: Empirical evidence and challenges revealed by plants. Proceedings of the Royal Society B. $277,3055-3064$.

Cipollini, D.F and J. Bergelson. (2002). Interspecific competition affects growth and herbivore damage of Brassica napus in the field. Plant Ecology 162(2): 227-231.

Cohen, D. (1966). Optimizing reproduction in a randomly varying environment. Journal of Theoretical Biology, 12: 119-129.

Danks, H.V. (2002). The range of insect dormancy responses. European Journal of Entomology, 99: $127-142$. 
de Jong, G. (1994). The fitness of fitness concepts and the description of natural selection. The Quarterly Review of Biology, 69 (1) 3:29.

de Jong, T., Klinkhamer, P. (2005). Evolutionary ecology of plant reproductive strategies. Cambridge University Press.

Delph, L.F., Weinig, C., Sullivan, K. (1998). Why fast-growing pollen tubes give rise to vigorous progeny: The test of a new mechanism. Proceedings of the Royal Society of London Series B-Biological Sciences, 265: 935-939.

Devlin, B. (1989) Components of seed and pollen yield of Lobelia cardinalis: Variation and correlations. American Journal of Botany, 76(2) 204-214.

Dobzhansky, T. (1955). A review of some fundamental concepts and problems of population genetics. Cold Spring Harbor Symposia on Quantitative Biology, 20:1-15

Dobzhansky, T. (1968). Population biology and evolution. Syracuse: Syracuse University Press.

Donnelly, S.E , Lortie, C.J., Aarssen, L.W.(1998). Pollination in Verbascum thapsus (Scrophulariaceae): The advantage of being tall. American Journal of Botany, 85(11):1618-1625. 
Doyon, J, Boivin ,G. (2005). The effect of development time on the fitness of female Trichogramma evanescens. Journal of Insect Science, 5(4):4.

Eckert, C.G. (1999). Clonal plant research: proliferation, integration, but not much evolution. American Journal of Botany, 86:1649-1654.

Ehrlen, J. (2015). Selection on flowering time in a life-cycle context. Oikos, 124: 92-101.

Endler, J. A. (1986). Natural selection in the wild. Princeton, NJ: Princeton Univ. Press

Engen, S. and Sæther, B.E. (2014). Evolution in fluctuating environments: Decomposing selection into additive components of the Robertson-Price equation. Evolution, 68: 854865.

Eriksson, O. and Jerling, L. (1990). Hierarchical selection and risk spreading in clonal plants. In J. van Groenendael and H. de Kroon (eds) Clonal Growth in Plants: Regulation and Function SPB Academic Publishing, The Hague, The Netherlands, pp. 79-94.

Eriksson, O. (1999). Seed size variation and its effect on germination and seedling performance in the clonal herb Convallaria majalis. Acta Oecologica, 20(1): 61-66

Falster, D. S., and Westoby, M. (2005). Trade-offs between height growth rate, stem persistence and maximum height among plant species in a post-fire succession. Oikos, 111:57-66. 
Feeny, P. (1976). Plant apparency and chemical defense. Recent Advances in Phytochemistry, 10: $1-40$.

Forrest, J. (2016). Complex responses of insect phenology to climate change. Current Opinion in Insect Science, 17:49-54.

Forrest, J., Rushing, A. (2010). Toward a synthetic understanding of the role of phenology in ecology and evolution. Philosophical Transactions of the Royal Society B, 365: 31013112.

Galen, C., Stanton, M.L. (1991) Consequences of emergence phenology for reproductive success in Ranunculus adoneus. American Journal of Botany, 78(7):978-988.

Garcia, M.M., Ehrlen, J. (2002). Reproductive effort and herbivory timing in a perennial herb: fitness components at the individual and population levels. American Journal of Botany, 89(8):1295-302 .

Geber, M. A., and Griffen, L.R. (2003). Inheritance and natural selection on functional traits. International Journal of Plant Sciences, 164:21-42. 
Geritz, S.A.H, Kisdi, E, Meszena, G., Metz, J.A.J. (1998) Evolutionarily singular strategies and the adaptive growth and branching of the evolutionary tree. Evolutionary Ecology, 12:3557.

Ghazoul, J. and Satake, A. (2009) Nonviable seed set enhances plant fitness: the sacrificial sibling hypothesis. Ecology, 90(2): 369-377

Giles, B.E. (1990). The effects of variation in seed size on growth and reproduction in the wild barley Hordeum vulgare ssp. spontaneum. Heredity, 64: 239:250

Godfrey-Smith, P. (2007). Conditions for evolution by natural selection. The Journal of Philosophy, 104(10): 489-516.

Green, A.J. (2001). Mass/length residuals: measures of body condition or generators of spurious results? Ecology, 82: 1473-1483.

Hannachi, S., Van Labeke, MC. (2018). Salt stress affects germination, seedling growth and physiological responses differentially in eggplant cultivars (Solanum melongena L.). Scientia Horticulturae, 228: 56-65.

Hansen, T. F. (2017). On the definition and measurement of fitness in finite populations. Journal of Theoretical Biology, 419: 36-43. 
Hedrick, P.W., Murray, E. (1983). Selection and measures of fitness, Genetics and Biology of Fitness. Academic Press; New York: p. 61-104.

Hereford, J. (2009). A quantitative survey of local adaptation and fitness trade-offs. The American Naturalist, 173(5):579-588.

Hughes, P.W, Jaworski, A.F., Davis, C.S., Aitken, S.M. and Simons, A.M. (2014). Development of polymorphic microsatellite markers for Indian Tobacco Lobelia inflata (Campanulaceae). Applications in Plant Sciences, 2: 1300096.

Hughes, P.W. and Simons A.M. (2014a). The continuum between semelparity and iteroparity: plastic expression of parity in response to season length manipulation in Lobelia inflata. BMC Evolutionary Biology, 14(90).

Hughes, P.W and Simons, A.M. (2014b) Changing reproductive effort within a semelparous reproductive episode. American Journal of Botany, 101(8): 1323-1331.

Hughes, P.W and Simons, A.M. (2014c). Secondary reproduction in the herbaceous monocarp Lobelia inflata: time-constrained primary reproduction does not result in increased deferral of reproductive effort. BMC Ecology, 14:15. 
Hughes, P.W and Simons A.M. (2015). Microsatellite evidence for obligate autogamy, but abundant genetic variation in the herbaceous monocarp Lobelia inflata (Campanulaceae). Journal of Evolutionary Biology, 28(11).

Jacobs, B.S and Lesmeister, S. A. (2012). Maternal environmental effects on fitness, fruit morphology and ballistic seed dispersal distance in an annual forb. Functional Ecology, 26: 588-597.

Kempthorne, O. and Pollak, E. (1970). Concepts of fitness in Mendelian populations. Genetics, 64: $125-145$.

Kimbrough, S.O. (1980). The concepts of fitness and selection in evolutionary biology. Journal of Social Biology Structure, 3: 149-170.

Koricheva, J. (2002). Meta-analysis of sources of variation in fitness costs of plant antiherbivore defenses. Ecology, 83(1) 176-190.

Lande, R. (1982). A quantitative genetic theory of life history evolution. Ecology, 63: 607-615.

Lande, R. and S. J. Arnold. (1983). The measurement of selection on correlated characters. Evolution, 37:1210-1226. 
Lehndal, L. and Ågren, J. (2015) Herbivory differentially affects plant fitness in three populations of the perennial herb Lythrum salicaria along a latitudinal gradient. PLoS ONE, 10(9): e0135939.

Lewontin, R. C. (1970). The units of selection. Annual Review of Ecology, Evolution, and Systematics, 1: 1-18.

Liu, H., Zhang, D., Yang, X., Huang, Z., Duan, S., Wang, X. (2014). Seed dispersal and germination traits of 70 plant species inhabiting the Gurbantunggut desert in Northwest China. The Scientific World Journal, 2014:346405.

Lortie, C.J. and Aarssen, L.W. (1999). The advantage of being tall: Higher flowers receive more pollen in Verbascum thapsus L. (Scrophulariaceae). Ecoscience, 6(1):68-71.

Lu, J., Tan, D.Y., Baskin, C.C., Baskin, J.M. (2017). Effect of seed position on parental plant on proportion of seeds produced with non-deep and intermediate physiological dormancy. Frontiers in Plant Science, 8: 147.

Mandal, M.S., Chakraborty, D., Gupta, K. (2008). Seed size variation: Influence on germination and subsequent seedling performance in Hyptis suaveolens (Lamiaceae), Research Journal of Seed Science, 1(1): 26-33. 
McArt, S.H. Salminen, J.P., Thaler, J.S., Halitschke, R., (2013) Leaf herbivory increases plant fitness via induced resistance to seed predators. Ecology, 94(4): 966-975.

McGraw, J.B, Caswell, H. (1996). Estimation of individual fitness from life-history data. The American Naturalist, 147(1): 47-64.

Meagher, T. R. (1986). Analysis of paternity within a natural population of Chamaelirium luteum 1. Identification of most-likely male parents. The American Naturalist, 128: 199215.

Metsare, M., Ilves, A., Haldna, M., Kull, T., Tali, K. (2015). Four seed-quality measures in orchids with different pollination systems. Acta Botanica Gallica, 162:4.

Metz, J.A.J., Nisbet, R. and Geritz, S.A.H. (1992). How should we define `fitness' for general ecological scenarios? Trends in Ecology and Evolution, 7, 198-202.

Metz, J. A. J. (2008). Fitness. In S. E. Jørgensen and B. D. Fath (Eds.). Encyclopedia of Ecology, vol 2., Elsevier, Oxford, pp. 1599-1612.

Metz, J., Liancourt P., Kigel, J., Harel, D., Sternberg, M., Tielborger, K. (2010). Plant survival in relation to seed size along environmental gradients: a long-term study from semi-arid and Mediterranean annual plant communities. Journal of Ecology, 98, 697-704. 
Milenkaya, O., Catlin, D.H., Legge, S., Walters, J.R. (2015) Body condition indices predict reproductive success but not survival in a sedentary, tropical bird. PLoS ONE, 10(8).

Miller, T.E.X, Williams, J.L, Jongejans, E., Brys, R., Jacquemyn, H. (2012). Evolutionary demography of iteroparous plants: incorporating non-lethal costs of reproduction into integral projection models. Proceedings of the Royal Society B. 279, 2831-2840.

Mills, S.K, Beatty, J.H. (1979). The propensity interpretation of fitness. Philosophy of Science, 46(2) 263-286.

Moles, A.T. and Westoby, M. (2004) Seedling survival and seed size: a synthesis of the literature. Journal of Ecology, 92, 372-383.

Mousseau, T.A., Roff, D.A. (1987). Natural selection and the heritability of fitness components. Heredity, 59: 181-197.

Nakamura, R. R. (1986). Maternal investment and fruit abortion in Phaseolus vulgaris, American Journal of Botany, 73, 1049- 1057.

Nuortila, C., Kytoviita, M.M., Tuomi, J. (2004). Mycorrhizal symbiosis has contrasting effects on fitness components in Campanula rotundifolia. New Phytologist, 164 : 543-553. 
O’Connell, L.M, Johnston, M.O. (1998). Male and female pollination success in a deceptive orchid, a selection study. Ecology, 79(4) 1246-1260.

Orr, H. A. (2009). Fitness and its role in evolutionary genetics. Nature Reviews Genetics, 10(8): $531-539$.

Papastylianou, P., Baokogianii, N.-N., Travlos, I., and Roussis, I. (2018). Sensitivity of Seed Germination to Salt Stress in Black Cumin (Nigella sativa L.). Notulae Botanicae Horti Agrobotanici Cluj-Napoca, 46(1), 202-205.

Pan, J. J., and Price, J. S. (2002). Fitness and evolution in clonal plants: the impact of clonal growth. Evolutionary Ecology, 15:583-600.

Philippi, T. and Seger, J. (1989). Hedging one's evolutionary bets, revisited. Trends in Ecology and Evolution, 4: 41-44.

Primack, R.B., Hyesoon, K. (1989). Measuring fitness and natural selection in wild plant populations. Annual Review of Ecology and Systematics, 20: 367-396.

Rafferty, N.E., CaraDonna, P.J., Burkle, L.A, Iler, A.M., Bronstein, J.L. (2013) Phenological overlap of interacting species in a changing climate: an assessment of available approaches. Ecology and Evolution, 3(9): 3183- 3193. 
Rand, D.A., Wilson, H.B. and McGlade, J.M. (1994) Dynamics and evolution: Evolutionarily stable attractors, invasion exponents and phenotype dynamics. Philosophical Transactions of the Royal Society B., 343, 261-283.

Rausher, M.D. (1992). The measurement of selection on quantitative traits: biases due to environmental covariances between traits and fitness. Evolution, 46:616-626.

Reekie, E. G. and F. Bazazz. (1987). Reproductive effort in plants. The American Naturalist, 129: 907-919.

Roff, D.A. (2002). Life history evolution. Sunderland: Sunauer Associates, Inc.

Seger, J. and Brockmann, H. J. (1987). What is bet-hedging? In Oxford surveys in evolutionary biology, vol. 4 (eds P. H. Harvey \& L. Partridge), pp. 182-211. Oxford, UK: Oxford University Press.

Silvertown, J. (2008). The evolutionary maintenance of sexual reproduction: evidence from the ecological distribution of asexual reproduction in clonal plants. International Journal of Plant Sciences, 169(1): 157-168.

Simons, A. M. and Johnston, M. O. (2000a). Variation in seed traits of Lobelia inflata (Campanulaceae): sources and fitness consequences. American Journal of Botany, 87: 124-132. 
Simons, A. M. and Johnston, M. O. (2000b). Plasticity and the genetics of reproductive behaviour in the monocarpic perennial, Lobelia inflata (Indian tobacco). Heredity, $85: 356-365$.

Simons, A.M. (2002). The continuity of microevolution and macroevolution. Journal of Evolutionary Biology, 15(5), 688-701.

Simons, A.M., and M.O. Johnston. (2003). Suboptimal timing of reproduction in Lobelia inflata may be a conservative bet-hedging strategy. Journal of Evolutionary Biology, 16:233243.

Simons, A.M., and M.O. Johnston. (2006). Environmental and genetic sources of diversification in the timing of seed germination: implications for the evolution of bet hedging. Evolution, 60 (11), 2280-2292.

Simons, A.M. (2007). Selection for increased allocation to offspring number under environmental unpredictability. Evolutionary Biology, 20:2.

Simons, A.M. (2011). Modes of response to environmental change and the elusive empirical evidence for bet hedging. Proceedings of the Royal Society B., 278:1601-1609. 
Smith, C. C., and S. D. Fretwell. (1974). The optimal balance between size and number of offspring. The American Naturalist, 108:499-506.

Sniegula, S., Golab, M.J., Johansson, F. (2016). Time constraint effects on phenology and life history synchrony in a damselfly along a latitudinal gradient. Oikos, 125: 414-423.

Sober, E. (1984). The nature of selection. Evolutionary Theory in Philosophy. MIT Press, Cambridge.

Sober, E. (2001). The two faces of fitness. In Singh, R. S., C. B. Krimbas, D. B. Paul and J. Beatty (Eds.). Thinking about evolution: Historical, Philosophical, and political perspectives. Cambridge University Press, pp. 309-321.

Souza, M.L., Fagundes, M. (2014). Seed size as a key factor in germination and seedling development of Copaifera langsdorffii (Fabaceae). American Journal of Plant Sciences, 5:2566-2573,

St Juliana, J.R., Janzen F.J. (2007). Can natural phenotypic variances be estimated reliably under homogeneous laboratory conditions? Journal of Evolutionary Biology, 20(4):1406-14.

Starrfelt, J. and Kokko, H. (2012) Bet-hedging — a triple trade-off between means, variances and correlations. Biological Reviews, 87:742-755. 
Stearns, S. C. (1976). Life history tactics: a review of the ideas. Quarterly Review of Biology, 51: $3-45$.

Stearns, S.C. (1992). The evolution of life histories. Oxford University Press, Oxford

Stocklin, J. and Favre, P. (1994). Effects of plant size and morphological constraints on variation in reproductive components in two related species of Epilobium. Journal of Ecology, 82(4): 735-746.

Strauss, S.Y. (1997). Floral characters link herbivores, pollinators and plant fitness. Ecology, 78(6) $1640-1645$.

Sutherland, S. and Delph, L.F. (1984). On the importance of male fitness in plants: Patterns of fruit-set. Ecology, 65(4): 1093-1104.

Taylor, D.R. Aarssen, L.W., Loehle, C. (1990). On the relationship between r/K selection and environmental carrying capacity: a new habitat templet for plant life history strategies. Oikos, 58: 239-25.

Thoday, J. (1953). Components of fitness. Symposium of the society for experimental biology, 7: 96-113.

Venable, D. L. (2007). Bet hedging in a guild of desert annuals. Ecology, 88, 1086- 1090. 
Vu, W.T., Chang, P.L., Moriuchi, K.S. Friesen, M.L. (2015). Genetic variation of transgenerational plasticity of offspring germination in response to salinity stress and the seed transcriptome of Medicago truncatula. BMC Evolutionary Biology, 15:59.

Wagner, P.G. (2009). The measurement theory of fitness. Evolution, 64(5): 1358-1376.

Weis, A., Wadgymar, S.M., Sekor, M., Franks, S.J. (2015). The shape of selection: using alternative fitness functions to test predictions for selection on flowering time. Evolutionary Ecology, 28:885-904.

Weis, A., Turner, K.M., Petro, B., Austen, E.J., Wadgymar, S.M. (2015) Hard and soft selection on phenology through seasonal shifts in the general and social environments: A study on plant emergence time. Evolution, 69-6: 1361-1374.

Williams, G. C. (1966). Adaptation and Natural Selection. Princeton: Princeton University Press.

Wiser, M.J., Ribeck, N., Lenski, R.E. (2013). Long-term dynamics of adaptation in asexual populations. Science, 342: 1364-1367.

Young, T. P. (1981). A general model of comparative fecundity for semelparous and iteroparous species. The American Naturalist, 118, 27-36. 
Younginger, B.S., Sirova, D., Cruzan, M.B., Ballhorn, D.J. (2017). Is biomass a reliable estimate of plant fitness? Applications in Plant Sciences, 5(2): 1600094.

Zimmerman, M., Gross, R.S. (1984). The relationship between flowering phenology and seed set in an herbaceous perennial plant, Polemonium foliosissimum Gray. The American Midland Naturalist, 111(1) 185-191.

\section{Appendices}

Appendix A Complete table of research articles used for the literature review 
A total of 147 articles obtained from Web of Science, Google Scholar and screened references lists for literature review. Articles included are the results of the search terms 'plant fitness', 'seed number', and 'offspring quality'. The column heading "Scenario" refers to the specific scenario the article is classified under ("PA"= plant architecture, "HB"= trade-offs between defense again herbivory and seed number, "BH"=bet-hedging, "VI"= variation in degree of iteroparity, "MF"= male and female fitness, "SA"= sexual vs. asexual reproduction, "SO"= selfing vs. outcrossed progeny, "OTHER"= density dependent effects, hybridization, maternal effects, pollination limitation, and symbiosis). Studies that have used seed count as a measure of fitness, or used an alternative metric to measure fitness were noted with a "Yes/No" under each column. The column heading "Metric" corresponds to the alternative metrics to measure plant fitness ("SS"= seed size, "TSM"= total seed biomass, "PB"=plant biomass, "SURV"= survival, "GERM"= germination, "SE"= seedling establishment, "MS"= male success). Studies that have acknowledged seed number as a biased estimate of fitness, justified its use, or provided solutions were noted with a "Yes/No" under each column. 


\begin{tabular}{|c|c|c|c|c|c|c|c|c|c|c|}
\hline Article name & Authors & $\begin{array}{l}\text { Yea } \\
\text { r }\end{array}$ & Journal & Scenario 1 & $\begin{array}{l}\text { Used seed } \\
\text { count? }\end{array}$ & $\begin{array}{l}\text { Used an } \\
\text { alternative } \\
\text { metric? }\end{array}$ & Metric & $\begin{array}{l}\text { Acknowled } \\
\text { ged? }\end{array}$ & Justified? & $\begin{array}{l}\text { Solutio } \\
\text { ns? }\end{array}$ \\
\hline $\begin{array}{l}\text { Between-species patterns } \\
\text { of covariation in plant size, } \\
\text { seed size and fecundity in } \\
\text { monocarpic herbs }\end{array}$ & $\begin{array}{l}\text { Aarssen, } \\
\text { L. }\end{array}$ & 2001 & Ecoscience & PA & Yes & Yes & $\begin{array}{l}\text { PB, SS, } \\
\text { TSM }\end{array}$ & No & No & No \\
\hline $\begin{array}{l}\text { Fecundity allocation in } \\
\text { herbaceous plants }\end{array}$ & $\begin{array}{l}\text { Aarssen, } \\
\text { L. }\end{array}$ & 1992 & Oikos & PA & Yes & Yes & $\begin{array}{l}\text { PB, } \\
\text { TSM }\end{array}$ & Yes & No & No \\
\hline $\begin{array}{l}\text { Genotypic variation in } \\
\text { fecundity allocation in } \\
\text { Arabidopsis thaliana }\end{array}$ & $\begin{array}{l}\text { Aarssen, } \\
\text { L. }\end{array}$ & 1992 & $\begin{array}{l}\text { Journal of } \\
\text { Ecology }\end{array}$ & PA & Yes & Yes & $\begin{array}{l}\text { PB, } \\
\text { GERM }\end{array}$ & No & Yes & No \\
\hline $\begin{array}{l}\text { Seedling establishment in } \\
\text { an epiphytic orchid : An } \\
\text { experimental study of seed } \\
\text { limitation }\end{array}$ & $\begin{array}{l}\text { Ackerman } \\
\text { et al. }\end{array}$ & 1996 & Oecologia & OTHER & No & Yes & $\begin{array}{l}\text { SE, } \\
\text { SURV }\end{array}$ & Yes & No & No \\
\hline $\begin{array}{l}\text { Effects of apical meristem } \\
\text { mining on plant fitness } \\
\text { architecture, and flowering } \\
\text { phenology in Cirsium } \\
\text { Altissum (Asteraceae) }\end{array}$ & $\begin{array}{l}\text { Adhikari } \\
\text { \& Russell }\end{array}$ & 2014 & $\begin{array}{l}\text { American } \\
\text { Journal of } \\
\text { Botany }\end{array}$ & $\mathrm{HB}$ & No & Yes & $\begin{array}{l}\text { GERM, } \\
\text { PB }\end{array}$ & No & No & No \\
\hline $\begin{array}{l}\text { Induced responses to } \\
\text { herbivory and increased } \\
\text { plant performance }\end{array}$ & $\begin{array}{l}\text { Agrawal, } \\
\text { A. }\end{array}$ & 1998 & Science & $\mathrm{HB}$ & Yes & No & & No & No & No \\
\hline $\begin{array}{l}\text { Transgenerational } \\
\text { consequences of plant } \\
\text { responses to herbivory: An } \\
\text { adaptive maternal effect? }\end{array}$ & $\begin{array}{l}\text { Agrawal, } \\
\text { A. }\end{array}$ & 2001 & $\begin{array}{l}\text { The } \\
\text { American } \\
\text { Naturalist }\end{array}$ & HB & No & Yes & $\begin{array}{l}\text { SS, } \\
\text { SURV }\end{array}$ & No & No & No \\
\hline $\begin{array}{l}\text { Costs of induced responses } \\
\text { and tolerance to herbivory } \\
\text { in male and female fitness } \\
\text { components of wild radish }\end{array}$ & $\begin{array}{l}\text { Agrawal, } \\
\text { A. }\end{array}$ & 1999 & Evolution & $\mathrm{HB}, \mathrm{MF}$ & Yes & Yes & $\mathrm{SS}, \mathrm{MS}$ & Yes & Yes & Yes \\
\hline $\begin{array}{l}\text { Reciprocal transplants } \\
\text { demonstrate strong } \\
\text { adaptive differentiation of }\end{array}$ & $\begin{array}{l}\text { Agren \& } \\
\text { Schemske }\end{array}$ & 2012 & $\begin{array}{l}\text { New } \\
\text { Phytologist }\end{array}$ & VP & Yes & Yes & $\begin{array}{l}\text { SURV, } \\
\text { SE }\end{array}$ & Yes & No & No \\
\hline
\end{tabular}


the model organism

Arabidopsis thaliana in its

native range

Pollination Success across

an Elevation and Sex Ratio

Gradient in Gynodioecious

Daphne laureola

$\begin{array}{ll} & \begin{array}{l}\text { American } \\ \text { Journal of }\end{array} \\ & \end{array}$

Plant patch structure

Alonso, C. 2005 Botany

MF

Yes

No

Yes

No

No

influences plant fitness via

antagonistic and

mutualistic interactions but Andersson

in different directions

et al.

2016 Oecologia

HB

Yes

Yes

GERM No

No

No

on adaptive potential for

leaf morphology in Crepis

tectorum (Asteraceae)

Experimental studies of

evolutionary significance

of sexual reproduction

Andersson

\& Ofori

Annals of

Antonovic

2013 Botany

SO, PA

No

Yes

SURV No

No

No

s \&

Ellstrand

1985 Evolution

SA

Yes

No

No

Yes

No

Pollen and Resource

Limitation in a

\&

Mutikaine

American

Gynodioecious Species

Within-plant variation in

reproductive investment:

consequences for selection

on flowering time

$\mathrm{n}$

Journal of

The causes of selection on

flowering time through

male fitness in a

hermaphroditic annual

plant

Estimating selection

through male fitness: three

complementary methods

illuminate the nature and

2005 Botany

$\mathrm{MF}$

Yes

Yes

TSM

No

No

No

Austen et

Journal of

al.

Evolutionar

2015

y Biology

$\mathrm{MF}$

Yes

Yes

MS

No

No

No

Austen EJ,

Weis AE

2016

Evolution

MF

Yes

No

No

Yes

Yes

Austen EJ,

of The

Weis AE

Royal

2016

Society B

MF

No

Yes

TSM,

MS

Yes

Yes

Yes 
causes of selection on

flowering time

What drives selection on

flowering time? An

experimental manipulation

of the inherent correlation

between genotype and

Austen EJ,

environment

Weis AE

2015 Evolution VP, PA, HB No

$\mathrm{PB}$,

Fitness constraints on

flower number, seed

number and seed size in

the dimorphic species

Primula farinosa and

America maritima

Baker \&

New

Effects of above- and

belowground herbivory on

growth, pollination, and

reproduction in cucumber

Seed production in

gentiana newberri

(Gentianaceae)

Richards

1994 Phytologist

MF

Yes

SS,

GERM No

No

No

Barber et

al

2011 Oecologia

HB

Yes

Yes

MS

No

No

No

Pollen limitation and its

influence on natural

Barnes \&

The Great

Rust

Basin

selection through seed set

Bartkowsk

1994 Naturalist

MF

Yes

No

No

No

No

a and

Evolutionar

Johnston

2015 y Biology

VP

Yes

No

No

No

No

sexual and asexual

reproduction in plants

living in variable

Journal of

environments

Bengtsson

Evolutionar

\& Ceplitis

2000 y Biology

SO

Yes

Yes

MS

Yes

No

No

Offspring performance in three cleistogamous Viola species

Plant

Do different measures of

maternal fitness affect

estimation of natural

\begin{tabular}{|c|c|c|c|c|c|}
\hline Berg et al. & 1999 & $\begin{array}{l}\text { Plant } \\
\text { Ecology }\end{array}$ & $\mathrm{SO}$ & Yes & Yes \\
\hline & & $\begin{array}{l}\text { Journal of } \\
\text { Plant }\end{array}$ & & & \\
\hline Bigio et al. & 2017 & Ecology & MF & Yes & Yes \\
\hline
\end{tabular}

\section{SS,}

GERM,

SURV,

$\begin{array}{lll}\text { PB No No No } & \end{array}$

Bigio et al. 2017 Ecology

Yes

Yes

TSM,

MS

Yes

Yes

Yes 
selection on floral traits? A

lesson from Linum

pubescens (Linaceae)

Climate adaptation is not

enough: warming does not

facilitate success of

southern tundra plant

populations in the high

Arctic

Seed production and pre-

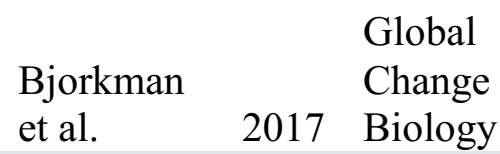

VP

No

Yes

PB, SE No

No

No

dispersal reproductive

losses in the narrow

endemic Euphorbia pedroi

(Euphorbiaceae)

Boieiro \&

Rego

Plant

Are mismatches the norm?

Timing of flowering,

fruiting, dispersal and

germination and their

fitness effects in Frangula

alnus (Rhamnaceae)

Adaptive value of

phenological traits in

stressful environments:

Predictions based on seed

production and laboratory

natural selection

Brachi et

Bolmgren

\&

Effects of experimental

al

Eriksson

2012 Ecology

HB

Yes

No

No

No

No

manipulation of

inflorescence on polliation

and pre-dispersal seed

predation in the

hummingbird-pollnated

plant Ipomopsis aggress

Brody \&

Mitchell

1997 Oecologia VP

Yes

Yes

SS

No

No

No

Success and Variation in

Fruit and Seed Set in

Brunet, J

1996

Ecology

MF

Yes

Yes

MS,

TSM

Yes

No

Yes 
Aquilegia Caerulea

Clonal Growth and Ramet

Performance in the

Woodland Herb, Asarum

Canadense

Cain and

\section{Journal of}

Effects of Floral Traits on

Sequential Components of

Fitness in Ipomopsis

aggregata

Damman

1997 Ecology

SA

Yes

SURV,

\begin{tabular}{|c|c|}
\hline & \\
\hline $\begin{array}{l}\text { Campbell, } \\
\text { Diane }\end{array}$ & 1991 \\
\hline
\end{tabular}

Selection for a floral trait

is not mediated by pollen

receipt even though seed

set in the population is

pollen-limited

Diane

1991 Naturalist

MF Yes

Yes

MS

Yes

Yes

No

\section{Is Plant Fitness}

Proportional to Seed Set?

An Experiment and a

Spatial Model

Competition alters life

history and increases the

relative fecundity of crop-

wild radish hybrids

(Raphanus spp.)

Isolated and Community

Contexts Produce Distinct

Responses by Host Plants

to the Presence of Ant-

Aphid Interaction: Plant

Productivity and Seed

Viability

Direct and indirect effects

of pollinators and seed

predators to selection on

plant and floral traits

Effects of florivory on

plant-pollinator

Campbell,

Diane

Functional

MF

Yes

No

No

No

No

The

Campbell,

American

PA,

Diane

2017 Naturalist

OTHER

Yes

No

No

No

Yes

Campbell

New

\& Snow

2007 Phytologist

OTHER,

HB Yes

Yes

PB

No

No

No

Canedo-

Junior et

al

2017 PLoS One

HB

Yes

TSM,

GERM Yes

No

No

Cariveau

et al

Carper et

2004 Oikos

MF

Yes

Yes

PB

Yes

2016 Journal of

HB, MF

Yes

Yes

MS

No

No
No

No 
interactions: Implications

for male and female

components of plant

reproduction

Selection on floral and carbon uptake traits of Lobelia siphilitica is similar in females and hermaphrodites

Seed production timing infl uences seedling fi tness in the tropical live oak Quercus oleoides of Costa Rican dry forests Offspring for the next generation: most are produced by small plants within herbaceous populations Spatial variation in pollinator-mediated selection on phenology, floral display and spur length in the orchid Gymnadenia conopsea Pollinator-mediated selection on flowering phenology and floral display in a distylous herb Primula alpicola Variation in sex ratio, morph-specific reproductive ecology and an experimental test of frequency-dependence in the gynodioecious
Botany

\begin{tabular}{|c|c|c|c|c|c|c|c|c|c|}
\hline $\begin{array}{l}\text { Caruso \& } \\
\text { Yakobows } \\
\text { ki }\end{array}$ & 2008 & $\begin{array}{l}\text { Journal of } \\
\text { Evolutionar } \\
\text { y Biology }\end{array}$ & MF & Yes & No & & Yes & No & No \\
\hline $\begin{array}{l}\text { Center et } \\
\text { al. }\end{array}$ & 2016 & $\begin{array}{l}\text { American } \\
\text { Journal of } \\
\text { Botany }\end{array}$ & VP & Yes & Yes & SE & No & Yes & No \\
\hline
\end{tabular}

Chambers,

Jesse;

Aarssen,

Lonnie W. 2009 y Ecology

PA

Yes

Yes

PB

No

Yes

No

Chapurlat

et al.

New

2015 Phytologist

Yes

No

No

No

No

Scientific VP, MF,

Chen et al. 2017 Reports

HB Yes

No

No

No

No

Journal of

Cuevas et

Evolutionar

al.

2008
MF

Yes

Yes

TSM

No

No

No 
Kallstroemia grandiflora

(Zygophyllaceae)

Responses of phenology

and seed production of

annual Koenigia islandica

to warming in a desertified

alpine meadow

\begin{tabular}{|c|c|c|c|c|c|c|c|c|c|}
\hline Cui et al. & 2017 & $\begin{array}{l}\text { Agricultural } \\
\text { and Forest } \\
\text { Meteorolog } \\
\text { y }\end{array}$ & MF & Yes & Yes & $\begin{array}{l}\text { SS, } \\
\text { TSM }\end{array}$ & No & No & No \\
\hline Devlin, B. & 1989 & $\begin{array}{l}\text { American } \\
\text { Journal of } \\
\text { Botany }\end{array}$ & $\mathrm{MF}$ & Yes & Yes & $\begin{array}{l}\text { MS, } \\
\text { TSM }\end{array}$ & Yes & Yes & Yes \\
\hline
\end{tabular}

Components of Seed and

Pollen Yield of Lobelia

cardinalis: Variation and

Correlations

Devlin, B. 1989 Botany

MF

TSM

on seed and fruit

production in highbush

blueberry cv. 'Bluecrop'

(Vaccinium corymbosum;

Ericaceae)

Dogterom Journal of

Pollination in Verbascum

Thapsus

(Scrophulariaceae): The

Advantage of Being Tall

The Evolution and

Maintenance of Monoecy

and Dioecy in Sagittaria

Latifolia (Alismataceae)

Sex allocation in clonal

plants: Might clonal

expansion enhance

fitness gains through

male function?

Botany

SO Yes

Yes

GERM No

No

No

Donnelly

American

et al.

Journal of

1998 Botany

PA, MF, SO Yes

Yes

PB

No

No

No

Dorken et

al

2002 Evolution

SA, SO

No

No

No

No

No

Proximate Limits to Seed

Production in a

Herbaceous Perennial

Dorken

and van

Drunen

Evolutionar

2010 y Ecology

SA

No

No

No

No

No

Legume, Lathyrus Vernus

Flowering schedule in a

Ehrlen,

Johan

Ehrlen et

1992 Ecology $\mathrm{MF}$
Ecology

VP, HB,

$\begin{array}{lllllll} & \text { Yes } & \text { Yes } & \text { TSM } & \text { No } & \text { No } & \text { No } \\ \text { VP, VI } & \text { Yes } & \text { No } & & \text { Yes } & \text { Yes } & \text { Yes }\end{array}$

No 
perennial plant; life-history a

trade-offs, seed predation,

and total offspring fitness

Timing of Flowering:

Opposed Selection on

Different Fitness

Components and Trait

Covariation

Ehrlen,

Johan

The

Naturalist

VP, HB Yes

Yes No

No No

No

Yes

of the

National

Academy of

Sciences of

Population size and

relatedness affect fitness of

a self-incompatible

the United

invasive plant

States of

Experimental Studies of

Elam et al 2007 America

SO

Yes

No

No

No

No

the Evolutionary

Significance of Sexual

Reproduction Ii. a Test of

the Density-Dependent

Ellstrand,

Selection Hypothesis

Norman

1985 Evolution

SA

No

Yes

PB

No

No

No

with pollination intensity

across populations of

Sabatia angularis

New

Climate change alters

reproductive isolation and potential gene flow

in an annual plant

Consequences of

Emergence Phenology for

Reproductive Success in

Ranunculus adoneus

Reproductive effort and

herbivory timing in a

Emel et al.
Franks and
Weis

\section{Phytologist}

VP, MF

Yes

Yes

PB

Yes

No

Yes

$\mathrm{y}$
$\mathrm{E}$

y Application

Weis 2009 s

Application

Galen \&
Stanton
Garcia,
MB;

American

Journal of

1991 Botany

American

MB;

2002 Journal of

VP

No

Yes

TSM

No

No

No

VP

VP Yes

HB, VP, VI Yes

Yes
Yes

$\begin{array}{ll}\text { SS, SE } & \text { No } \\ \text { SURV, } & \\ \text { PB } & \text { Yes }\end{array}$

No

No

No

No 
perennial herb: Fitness

components at the

individual and population

levels

Nonviable seed set

enhances plant fitness: the sacrificial sibling

hypothesis

Timing is everything: does early and late germination favor invasions by

herbaceous alien plants?

Population Sex Structure and Reproductive Fitness in Gynodioecious Sidalcea malviflora

Bet hedging in desert

winter annual plants:

Optimal germination strategies in a variable environment

Are tetraploids more successful? Floral signals, reproductive success and floral isolation in mixedploidy populations of a terrestrial orchid Effects of Pollen and Resources on Seed

Number and Other Fitness

Components in

Amelanchier arborea (

Rosaceae : Maloideae )

Sources and Consequences of Seed Size Variation in

Lupinus Perennis
Ehrlen, J

Botany
Ghazoul \&

Satake

2009 Ecology

SO

Yes

No

No

Yes

No

Gioria et

al.

Journal of

Plant

2018 Ecology

VI, VP

No

No

No

No

No

Graff,

Alison

1999 Evolution

MF

Yes

Yes

TSM

No

No

No

\section{Gremer}

and

Venable

Ecology

2014 Letters

BH

No

Yes

GERM,

SURV,

PB

No

No

No

Gross \&

Schiestl

Annals of

2015 Botany

MF

Yes

No

No

Yes

No

American

Journal of

Gorchov

1988 Botany

MF

Yes

Yes

TSM

No

No

Halpern,

Journal of

Stacey

2005
PA

Yes

Yes

TSM,

GERM, Yes

No

No 
(Fabaceae): Adaptive and

non-adaptive hypotheses

Induced Floral and

Extrafloral Nectar

Production Affect Ant-

Hernandez

pollinator Interactions and

Cumplido

Plant Fitness

et al.

2016 BioTropica HB

Yes

No

No

No

No

Unpredictability and

Plastic Energy Allocation

Strategies in Polygonum

Cascadense (Polygonaceae

Hickman

Journal of

Herbivore-induced

changes in ower scent and morphology affect the structure of ower-visitor networks but not plant reproduction

Hoffmeist

Seed set variation in wild

Clarkia populations:

teasing apart the effects of seasonal resource

depletion, pollen quality, and pollen quantity 1975 Ecology

VI

Yes

PB, er et al.

2016 Oikos

HB

Yes

TSM,

GERM No

No

No

Predicted global warming scenarios impact on the mother plant to alter seed dormancy and germination behaviour in Arabidopsis The continuum between semelparity and iteroparity: plastic expression of parity in response to season length manipulation in Lobelia inflata

Si

\begin{tabular}{|c|c|c|c|c|c|c|c|c|c|}
\hline Hove et al. & 2016 & $\begin{array}{l}\text { Ecology } \\
\text { and } \\
\text { Evolution }\end{array}$ & VP, SO & Yes & No & & No & No & No \\
\hline $\begin{array}{l}\text { Huang et } \\
\text { al. }\end{array}$ & 2018 & $\begin{array}{l}\text { Plant, Cell } \\
\& \\
\text { Environmen } \\
t\end{array}$ & $\mathrm{BH}, \mathrm{VP}$ & Yes & Yes & $\begin{array}{l}\text { SS, } \\
\text { TSM, } \\
\text { GERM }\end{array}$ & Yes & No & No \\
\hline $\begin{array}{l}\text { Hughes \& } \\
\text { Simons }\end{array}$ & 2014 & $\begin{array}{l}\text { BMC } \\
\text { Evolutionar } \\
\text { y Biology }\end{array}$ & VI, VP & Yes & Yes & SS, PB & No & No & No \\
\hline
\end{tabular}


Changing reproductive effort within a semelparous reproductive episode Secondary reproduction in the herbaceous monocarp Lobelia inflata: timeconstrained primary reproduction does not result in increased deferral of reproductive effort Maternal environmental effects on fitness, fruit morphology and ballistic seed dispersal distance in an annual forb

The effects of quantitative fecundity in the haploid stage on reproductive success and diploid fitness in the aquatic peat moss Sphagnum macrophyllum Pollen Limitation of

Female Reproduction in Lobelia Cardinalis and L. Siphilitica

Effects of Cross and SelfFertilization on Progeny

Fitness in Lobelia cardinalis and L. Context-dependent autonomous selffertilization yields reproductive assurance and mixed mating

Temporal Variation of Flower and Fruit Size in
Hughes \&
American
Simons
Journal of

VI

Yes

Yes

SS

No

Yes

No

Hughes \&

BMC

Simons

2014 Ecology

VI, VP

Yes

Yes

SURV,

PB No

No

No

Jacobs \& Functional PA,

Lesmeister 2012 Ecology OTHER

Yes

No

No

Yes

No

Johnson \&

Shaw

2016 Heredity

SA

No

Yes

SS, PB No

No

No

Johnston,

Mark

1991 Ecology

MF

Yes

Yes

TSM

No

No

No

Johnston,

Mark

1992 Evolution

SO

Yes

Yes

SS,

TSM Yes

Yes

No

TSM,

Kalisz et al. Kang \&

2004 Nature

SO

Yes

SURV, Primack
American

1991 Journal of

VP, PA

Yes

Yes

\section{PB}

PB,

TSM

No

No

No

Yes No

Yes

Yes Yes

Yes


Relation to Seed Yield in

Botany

Celandine Poppy

Effects of Herbivores on

Growth and Reproduction of their Perennial Host,

Karban \&

Erigeron Glaucus

Growth, phenology, and seed viability between glyphosate-resistant and glyphosate-susceptible hairy fleabane

Reduced fecundity and o spring performance in small populations of the declining grassland plants Primula veris and Gentiana lutea

Strauss

1993 Ecology

HB

Yes

Yes

TSM,

PB,

Kaspary et

al.

2017 Bragantia

HB

Yes

Yes

SURV No

No

No

Maternal effects and

heterosis influence the

fitness of plant hybrids

Optimal defense theory

explains deviations from

latitudinal herbivory

defense hypothesis

The Effect of Floral

Herbivory on Male and

Female Reproductive

Success in Isomeris

arborea

The Consequences of

Floral Herbivory for

Pollinator Service to

Isomeris arborea

Effects of pollination

intensity on offspring

number and quality in a
Journal of

Kery et al. $\quad 2000 \quad$ Ecology

Yes

Yes

$\mathrm{SS}$,

TSM

No

No

No

No

Kirk et al -2005 New

New

OTHER

No

Yes

PB

No

No

No

No

Kooyers et

al.

2017 Ecology

HB

No

Yes

GERM No

No

No

Krupnick

\& Weis

1999 Ecology

HB, MF

Yes

Yes

SURV No

No

No

Krupnick

et al

1999 Ecology

HB, MF

Yes

No

Labouche

Journal of

2017 Ecology

MF

Yes

Yes

SS,

TSM,

et al.

2017 Ecology

MF

No

Yes

No

SURV, Yes

Yes No
SO, PA 
wind-pollinated herb

Herbivory Differentially

Affects Plant Fitness in

Three Populations of the

Perennial Herb Lythrum

salicaria along a

Lehndal \&

Latitudinal Gradient

Agren

2015 PLoS One

HB

Yes

Yes

PB

No

No

No

phenology, growth,

defense, and reproduction

to interactive effects of

warming and insect

herbivory

Effects of Sowing Date on

Lemoine

et al.

2017 Ecology

HB, VP

Yes

Yes

Yes

Yes

No

Phenotypic Plasticity of

Fitness-Related Traits in

Two Annual Weeds on the

Songnen Plain of China

Li et al.

2015 PLoS One VP

Yes

PB,

Life history trait

differentiation and local

adaptation in invasive

populations of Ambrosia

artemisiifolia in China

Li et al. 2015 Oecologia MF, VP, PA Yes

PB,

Experimental inbreeding

reduces seed production

and germination

independent of

fragmentation of

populations of Swertia

perennis

Lack of early inbreeding

depression and distribution

of selfing rates in the

neotropical emergent tree

Ceiba Pentandra:

Assessment from several

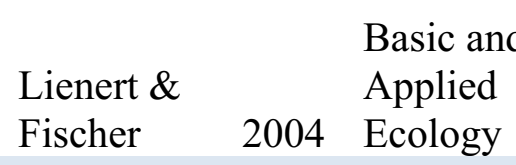

SO

Yes

GERM,

TSM

No

No

No

American

Journal of

Lobo et al. 2015 Botany
SO
TSM,

GERM,
Yes

Yes
No
No 
reproductive events

The advantage of being

tall: Higher flowers receive

more pollen in Verbascum

thapsus L.

(Scrophulariaceae)1

Lortie \&

Aarssen

1999 Ecoscience

PA

Yes

Yes

PB

No

No

No

season on life history traits

and on transgenerational

plasticity in seed dormancy

in a cold desert annual

Enforced Clonality

Scientific

Lu et al. 2016 Reports

VP

Frontiers in

Confers a Fitness

Martínkov

Plant

Advantage

á and

Effects of herbivore-

Klimešová

2016 Science

SA

\section{Canadian}

Journal of

\section{Forest}

nutrient resorption in scrub

oak (Quercus ilicifolia)

May and

$\mathrm{k}$

1995 Research

HB

Yes

Yes

PB

GERM,

Fitness consequences of

occasional outcrossing in a

functionally asexual plant

(Oenothera biennis)

Maron et

al.

2018 Ecology

$\mathrm{SO}, \mathrm{HB}$

Yes

No

No

No

No

Leaf herbivory increases

plant fitness via induced

resistance to seed predators at.

Avoiding the crowds: the

McArt et

al.

2013 Ecology

HB

Yes

No

No

Yes

No

evolution of plastic

responses to seasonal cues

in a density-dependent

world

Metcalf et

al.

Journal of

Four seed-

2015 Ecology

$\mathrm{BH}$

No

Yes

GERM No

Yes

No

quality measures in orchids with different pollination

systems

Metsare et

Botany

al 2015 Letters

Letters SO

SO
VP

Yes

Yes

GERM,

Parental environmental

Metz et al.

2015 Journal of

VP

Yes

Yes

SURV Yes

Yes

Yes

No 
effects due to contrasting watering adapt competitive ability, but not drought tolerance, in offspring of a semi-arid annual

Brassicaceae

Relative performance of selfed and outcrossed progeny in Impatiens capensis

Inbreeding Depression and

Maternal Effects in

Aquilegia Caerulea, a

Partially Selfing Plant

Effects of climate on

reproductive investment in

a masting species:

assessment of climatic

predictors and underlying

mechanisms

Moreira et

al.

Mitchell-

Odds,

Waller

1985 Evolution

SO

Montalvo,

Arlee

1994 Ecology

SO

Yes

Yes

TSM

Yes

Yes

Yes

Clonal growth and its

effects on male and female

reproductive success in

Prunus ssiori (Rosaceae)

Fitness Impacts of

Herbivory through Indirect

Effects on Plant-Pollinator

Interactions in Oenothera

macrocarpa

Contrasting effects of

ploidy level on seed production in a diploid-

tetraploid system

Inbreeding Depression in

Gynodioecious Lobelia

siphilitica: Among-Family

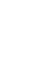

Yes

\section{GERM,}

PB

No

No No 
Differences Override

Between-Morph

Differences

Sex expression and

inbreeding depression in progeny derived from an extraordinary

hermaphrodite of Salix subfragilis

Mycorrhizal symbiosis has contrasting effects on

fitness components in

Campanula rotundifolia

Pollinators exert natural selection on flower size and floral display in

Penstemon digitalis

Macroevolutionary

constraints to tolerance: trade-offs with drought

tolerance and phenology,

but not resistance

Adaptation of flowering phenology and fitnessrelated traits across environmental gradients in the widespread Campanula rotundifolia

Male and Female

Pollination Success in a

Deceptive Orchid, a

Selection Study

The shape of the female

fitness curve for

Cynoglossum officinale:

Quantifying seed dispersal

Nagamitsu

and

Futamara

Botanical

Studies

SO

Yes

Yes

Nuortila et

al.

New

2004 Phytologist

OTHER

Yes

New

Parachno

witsch et

al.

2010 Phytologist

HB

Yes

No

Yes

Yes

Yes

Pearse et

al.

2017 Ecology

HB

Yes

Yes

PB

No

No

No

Preite et

al.

Evolutionar

2015 y Ecology

VP

Yes

No

Yes

No

No

O'Connell

and

Johnston

1998 Ecology

VP, MF, PA Yes

Yes

MS

No

GERM,

$r$ and de

Jong

Plant

1999 Biology

PA

Yes

Yes
PB

Yes

Yes 
and seedling survival in

the field

Fitness-consequences of geitonogamous selfing in a clonal marine angiosperm

(Zostera marina)

Frequency dependent

fitness in gynodecious

Lobelia siphilitica

Reproductive

consequences of variation

in flowering phenology in

the dry forest tree

Enterolobium cyclocarpum Rocha et

in Guanacaste, Costa Rica

al

Journal of

Evolutionar

Reusch, T 2001 y Biology

SO, SA

Yes

Yes

GERM,

Rivkin et

al.

2015 Evolution MF, PA Yes

No

SURV

No

No

No

The effects of plant size

and light availability on

male and female

reproductive success and

functional gender in a

Setsuko

hermaphrodite tree species, and

Magnolia stellata

Tomaru

2011 Botany

PA, MF

Yes

Yes

MS

Yes

Yes

Yes

allocation to offspring

number under

environmental

Simons,

Journal of

unpredictability

Andrew

2007

Evolutionar

Suboptimal timing of

reproduction in Lobelia

inflata may be a

conservative bet-hedging

strategy

Environmental and

Genetic Sources of

Diversification in the

Timing of Seed

$\begin{array}{lll} & & \text { Journal of } \\ \text { Simons \& } & & \text { Evolutionar } \\ \text { Johnston } & 2003 & \text { y Biology }\end{array}$

BH, VP Yes

Yes

PB

No

No

No

\section{Simons}

and

Johnston

2006

Evolution

$\mathrm{BH}$

Yes

Yes

SS,

GERM No

No No 
Germination: Implications

for the Evolution of Bet

Hedging

Variation in seed traits of

Lobelia inflata

(Campanulaceae): Sources

and Fitness Consequences

Simons \&

American

Johnston

Journal of

Consequences of Floral

Variation for Male and

Female Reproduction in

Experimental Populations

of Wild Radish, Raphanus

sativus $\mathrm{L}$.

Ecological Consequences

and Phenotypic Correlates

of Petal Size Variation in

Wild Radish, Raphanus

sativus (Brassicaceae)

Reproductive performance

of Helianthemum caput-

felis along its fragmented

distribution in the

Mediterranean coasts

On the Importance of Male

Fitness in Plants: Patterns

of Fruit-Set

Interacting effects of

genetic variation for seed

dormancy and flowering

time on phenology, life

history, and fitness of

experimental Arabidopsis

thaliana populations over

multiple generations in the

fiel

Antiherbivore defenses

Stanton et

al.

1991 Evolution

American

Stanton \&

Preson

1988

Journal of

Botany

Sulis et al. $2017 \quad$ Flora

\& Delph

1984 Ecology

Taylor et
al.

Thompson

2017

New
MF

Yes

MF

Yes

Yes

TSM

No

No

No

VP, MF

Yes

No

Yes

No

MF

Yes

2017 Phytologist

VP
HB

No
No

Yes

Yes

PB
TSM

Yes
No

es

$\sqrt{2}$

$\begin{array}{ll}\text { Yes } & \text { No } \\ \text { No } & \text { No }\end{array}$


alter natural selection on

plant reproductive traits

Trade-offs between clonal and sexual reproduction in sagittaria latifolia

(alismataceae) scale up to affect the fitness of entire clones

Consequences of clonality for sexual fitness: Clonal expansion enhances fitness under spatially restricted dispersal Parasitoid-plant mutualism: parasitoid attack of herbivore increases plant reproduction Floral Plasticity in an Iteroparous Plant: The Interactive Effects of Genotype, Environment, and Ontogeny in Campanula rapunculoides ( Campanulaceae ) Inbreeding depression in Campanula rapunculoides L. I. A comparison of inbreeding depression in plants derived from strong and weak self-

incompatibility phenotypes Correlated patterns of

\section{\& Johnson}

Van-

drunen \& New

Dorken

2012 Phy

Procec

SA, MF Yes

Yes

PB

No

No

No

of the

National

Academy of

Sciences of

Van-

Drunen et

the United

al

States of

2015 America

Entomologi

a

Experiment

van-Loon

alis et

et al.

2000 Applicata

HB

Yes

American

Journal of

Vogler et

al.

1999 Botany

MF

Yes

Yes

MS

No

No

No

\begin{tabular}{|c|c|c|c|c|c|c|c|c|}
\hline $\begin{array}{l}\text { Vogler et } \\
\text { al. }\end{array}$ & 1999 & $\begin{array}{l}\text { Journal of } \\
\text { Evolutionar } \\
\text { y Biology }\end{array}$ & SO & Yes & Yes & $\begin{array}{l}\text { GERM, } \\
\text { SURV, } \\
\text { PB }\end{array}$ & Yes & No \\
\hline Volis, & 2007 & Evolutionar & VP & Yes & Yes & $\mathrm{SS}$ & No & No \\
\hline
\end{tabular}


variation in phenology and

populations of two annual grasses along an aridity gradient

Seed Set and Seed Mass in

Ipomopsis aggregata :

Variance Partitioning and

Inferences about

Waser et

Postpollination Selection

al

1995

Evolution

$\mathrm{MF}, \mathrm{SO}$

Yes

Yes

TSM

No

No

No

using alternative fitness

functions to test

predictions for selection on

flowering time

Evolutionar

Hard and soft selection on

phenology through

seasonal shifts in the

general and social

environments: A study on

plant emergence time

Weis et al. 2014 y Ecology

VP

Yes

No

No

No

No

The snow and the willows:

earlier spring snowmelt

reduces performance in the

low-lying alpine shrub

Salix herbacea

Wheeler et

Floral Dimorphism,

Pollination, and Self-

Fertilization in

Gynodioecious Geranium Williams

richardsonii (Geraniaceae) et al.

et al. $\quad 2000$

Journal of

Parasitoid wasps indirectly

suppress seed production

by stimulating

consumption rates of their

seed-feeding hosts

Weis et al. 2015 Evolution

VP

Yes

Yes

SURV,

PB

No

No

No

$2016 \begin{array}{ll}\text { Journal of } \\ \text { Ecology }\end{array}$

VP, SA

Yes

Yes

PB

No

No

No

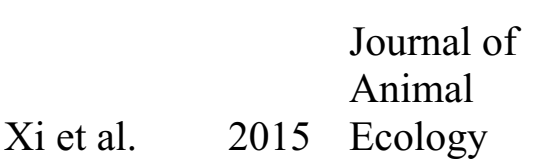

SO, MF

Yes

Yes

MS

No

No

No

Xi et al. 2015 Ecology

HB

Yes

No

No

No

No 
Influences of Floral

Variation on Pollen

Removal and Seed

Production in Wild Radish

Young et

The relationship between

flowering phenology and seed set in an herbaceous perennial plant,

polemonium foliosissimum

gray

al

1990 Ecology

MF

Yes

Yes

MS

No

No

No

$\begin{array}{lll} & & \text { The } \\ \text { Zimmerm } & & \text { American } \\ \text { an and } & & \text { Midland } \\ \text { Gross } & 1984 & \text { Natura } \\ \text { Zuest, } & & \\ \text { Tobias; } & & \\ \text { Rasmann, } & & \\ \text { Sergio; } & & \\ \text { Agrawal, } & & \\ \text { Anurag A. } 2015 & \text { Oikos }\end{array}$

The

Growth-defense tradeoffs

for two major anti-

herbivore traits of the

common milkweed

Asclepias syriaca

Anurag A. 2015 Oikos

HB

No

Yes

PB

Yes

No

Yes 


\section{Literature Cited in Appendix A}

Aarssen L.W and Taylor, D.R. (1992). Fecundity allocation in herbaceous plants. Oikos 65(2): 225-232.

Aarssen, L.W. and Clauss, M.J. (1992). Genotypic variation in fecundity allocation in Arabidopsis Thaliana. Journal of Ecology 80(1):109-114.

Aarssen, L. and Jordan, C. (2001). Between-species patterns of covariation in plant size, seed size and fecundity in monocarpic herbs. Écoscience, 8(4):471-477.

Ackerman, J.D., Sabat, A., Zimmerman, J.K. (1996). Seedling establishment in an epiphytic orchid: An experimental study of seed limitation. Oecologia, 106(2):192-198.

Adhikari, S.; Russell, F.L. (2014). Effects of apical meristem mining on plant fitness architecture, and flowering phenology in Cirsium Altissum (Asteraceae). American Journal of Botany, 101(12): 2079-2087.

Agrawal, A.A. (1998). Induced responses to herbivory and increased plant performance. Science, 279(5354):1201-1202.

Agrawal, A.A. (1999). Transgenerational Consequences of Plant Responses to Herbivory: An Adaptive Maternal Effect? The American Naturalist, 157(5): 555-569. 
Agrawal, A.A., Stout, M.J., Strauss, S.Y. (1999). Costs of induced responses and tolerance to herbivory in male and female fitness components of wild radish. Evolution, 53(4):10931104.

Argen, J, and Schemske, D.W. (2012). Reciprocal transplants demonstrate strong adaptive differentiation of the model organism Arabidopsis thaliana in its native range. New Phytologist, 194(4): 1112-1122.

Alonso, C. (2005). Pollination success across an elevation and sex ratio gradient in gynodioecious Daphne laureola. American Journal of Botany, 92(8):1264-1269.

Andersson, S. Ofori, J.K. (2013). Effects of mating system on adaptive potential for leaf morphology in Crepis tectorum (Asteraceae). Annals of Botany, 112(5):947-955.

Andersson, P., Ehrlen, J., Hamback, P.A. (2016). Plant patch structure influences plant fitness via antagonistic and mutualistic interactions but in different directions. Oecologia, 180(4):1175-1182.

Antonovics, J. and Ellstrand, N.C. (1985). Experimental studies of evolutionary significance of sexual reproduction. Evolution, 39(3):657-666. 
Asikainen, E. and Mutikainen, P. (2005). Pollen and resource limitation in a gynodioecious species. American Journal of Botany, 92(3):487-494.

Austen, E.J., Weis, A.E., Forrest, J.R.K. (2015). Within-plant variation in reproductive investment: consequences for selection on flowering time. Journal of Evolutionary Biology, 28(1):65-79.

Austen, E.J., Weis, A.E. (2015). Estimating selection through male fitness: three complementary methods illuminate the nature and causes of selection on flowering time. Proc Biol Sci 283(1825).

Austen, E.J., Weis, A.E. (2015). What drives selection on flowering time? An experimental manipulation of the inherent correlation between genotype and environment. Evolution 69(8): 2018-2033.

Austen, E.J., Weis, A.E. (2016). The causes of selection on flowering time through male fitness in a hermaphroditic annual plant. Evolution, 70(1):111-125.

Baker, R., Richards, A.J, K., Tremayne, M.(1994). Fitness constraints on flower number, seed number and seed size in the dimorphic species Primula farinosa and America maritima. New Phytologist, 128(3):563-570. 
Barber, N.A., Bernardo, H.L., Adler, L.S. (2011). Effects of above- and belowground herbivory on growth, pollination, and reproduction in cucumber. Oecologia, 165(2):377-386.

Barnes, M.E., Rust, R.W.(1994). Seed production in Gentiana newberri (Gentianaceae). Great Basin Naturalist, 54(4):351-358.

Bartkowska, M.P., Johnston, M.O. (2015). Pollen limitation and its influence on natural selection through seed set. Journal of Evolutionary Biology, 28(11):2097-2105.

Bengtsson, B.O., Ceplitis, A.(2000). The balance between sexual and asexual reproduction in plants living in variable environments. Journal of Evolutionary Biology, 13(3):415-422.

Berg, H., Redbo-Torstensoon, P. (1999). Offspring performance in three cleistogamous Viola species. Plant Ecology, 145(1):49-58.

Bigio, L., Lebel, M., Sapir, Y. (2017). Do different measures of maternal fitness affect estimation of natural selection on floral traits? A lesson from Linum pubescens (Linaceae). Journal of Plant Ecology, 10(2):406-413.

Bjorkman, A.D., Frei, E.R., Henry, G.H.R., Vellend, M. (2017). Climate adaptation is not enough: warming does not facilitate success of southern tundra plant populations in the high Arctic. Global Change Biology, 23(4):1540-1551. 
Boieiro, M.B., Serrano, A.R.M., Rego, C., Espadaler, X. (2012). Seed production and predispersal reproductive losses in the narrow endemic Euphorbia pedroi (Euphorbiaceae). Plant Ecology, 213(4):581-590.

Bolmgren, K., Eriksson, O.(2015). Are mismatches the norm? Timing of flowering, fruiting, dispersal and germination and their fitness effects in Frangula alnus (Rhamnaceae). Oikos, 124(5):639-648.

Brachi, B., Aime, C., Glorieux, C., Roux, F., Cuguen, J.(2012). Adaptive value of phenological traits in stressful environments: Predictions based on seed production and laboratory natural selection. PLoS One, 7(3).

Brody, A.K., Mitchell, R.J. (1997). Effects of experimental manipulation of inflorescence on polliation and pre-dispersal seed predation in the hummingbird-pollnated plant Ipomopsis aggress. Oecologia, 110(1):86-93.

Brunet, J. (1996). Male Reproductive Success and Variation in Fruit and Seed Set in Aquilegia Caerulea. Ecology, 77(8):2458-2471.

Cain, M.L., Damman, H.(1997). Clonal growth and ramet performance in the woodland werb, Asarum canadense. Journal of Ecology, 85(6):883-897. 
Campbell, D.R. (1991). Effects of floral traits on sequential components of fitness in Ipomopsis aggregata. The American Naturalist, 137(6):713-737.

Campbell, D.R., Bischoff, M. (2013). Selection for a floral trait is not mediated by pollen receipt even though seed set in the population is pollen-limited. Functional Ecology, 27(5):11171125.

Campbell, D.R., Brody, A.K., Aldridge, G., Waser, N.M., Price, M.V. (2017). Is plant fitness proportional to seed set? An experiment and a spatial model. The American Naturalist, 190(6):818-827.

Campbell, L.G., Snow, A.A. (2007). Competition alters life history and increases the relative fecundity of crop-wild radish hybrids (Raphanus spp.). New Phytologist, 173(3):648-660.

Canedo-Júnior, E.O., Santiago, G.S., Zurlo, L.F., Ribas, C.R., Carvalho, R.P., Alves, G.P., Carvalho, M.C.S., Souza, B. (2017). Isolated and community contexts produce distinct responses by host plants to the presence of ant-aphid interaction: plant productivity and seed viability. PloS one, 12(1).

Cariveau, D., Brody, A.K., Von Der Ohe, A., Garcia-Mayeya, L.S., Irwin, R.E. (2004). Direct and indirect effects of pollinators and seed predators to selection on plant and floral traits. Oikos, 104(1):15-26. 
Carper, A.L., Adler, L.S., Irwin, R.E. (2016). Effects of florivory on plant-pollinator interactions: Implications for male and female components of plant reproduction. American Journal of Botany, 103(6):1061-1070.

Caruso, C.M., Yakobowski, S.J. (2008). Selection on floral and carbon uptake traits of Lobelia siphilitica is similar in females and hermaphrodites. Journal of Evolutionary Biology, 21(6):1514-1523.

Center, A., Cavender-Bares, J., Etterson, J.R., Deacon, N.J. (2016). Seed production timing influences seedling fitness in the tropical live oak Quercus oleoides of Costa Rican dry forests. American Journal of Botany, 103(8):1407-1419.

Chambers, J., Aarssen, L.W. (2009). Offspring for the next generation: most are produced by small plants within herbaceous populations. Evolutionary Ecology, 23:737-751.

Chapurlat, E., Agren, J., Sletvold, N. (2015). Spatial variation in pollinator-mediated selection on phenology, floral display and spur length in the orchid Gymnadenia conopsea. New Phytologist, 208(4):1264-1275.

Chen, L., Zhang, B., Li, Q.(2017). Pollinator-mediated selection on flowering phenology and floral display in a distylous herb Primula alpicola. Scientific Reports, 7(13157): DOI:10.1038/s41598-017-13340-0. 
Cuevas, E., Monlina-Freaner, F., Parker, I.M. (2008). Variation in sex ratio, morph-specific reproductive ecology and an experimental test of frequency-dependence in the gynodioecious Kallstroemia grandiflora (Zygophyllaceae). Journal of Evolutionary Biology, 21(4):1117-1124.

Cui, S., Meng, F., Suonan, J., Wang, Q., (2017). Responses of phenology and seed production of annual Koenigia islandica to warming in a desertified alpine meadow. Agricultural and Forest Meteorology, 247:376-384.

Devlin, B. (1989). Components of seed and pollen yield of Lobelia cardinalis: Variation and correlations. American Journal of Botany, 76(2):204-214.

Dogteron, M.H., Mukai, A., Winston, M.L. (2000). Effect of pollen load size and source (self, outcross) on seed and fruit production in highbush blueberry cv. 'Bluecrop' (Vaccinium corymbosum; Ericaceae). American Journal of Botany, 87(11):1584-1591.

Donnelly, S.E., Lortie, C.J., Aarssen, L.W. (1998). Pollination in Verbascum thapsus (Scrophulariaceae): The Advantage of Being Tall. American Journal of Botany, 85(11):1618-1625.

Dorken, M.E., Friedman, J., Barrett, S.C. (2002). The evolution and maintenance of monoecy and dioecy in Sagittaria latifolia (Alismataceae). Evolution, 56(1):31-41. 
Dorken, M.E., W.E.,Van Drunen.(2010). Sex allocation in clonal plants: Might clonal expansion enhance fitness gains through male function? Evolutionary Ecology, 24(6):1463-1474.

Ehrlen, J. (1992). Proximate limits to seed production in a herbaceous perennial legume, Lathyrus Vernus. Ecology, 73(5):1820-1831.

Ehrlen, J., Raabova, J., Dahlgren, J.P. (2015). Flowering schedule in a perennial plant; lifehistory trade-offs, seed predation, and total offspring fitness. Ecology, 96(8):2280-2288.

Ehrlen, J., Munzbergova, Z.(2009) Timing of flowering: Opposed selection on different fitness components and trait covariation. The American Naturalist, 173(6):819-830.

Elam D.R., Ridley CE, Goodell, K., Ellstrand, N.C. (2007). Population size and relatedness affect fitness of a self-incompatible invasive plant. Proceedings of the National Academy of Sciences of the United States of America, 104(2):549-552.

Ellstrand, N.C., Antonovics, J. (1985). Experimental studies of the evolutionary significance of sexual reproduction I. A test of the density-dependent selection hypothesis. Evolution, 39(3): 657-666.

Emel, S.L., Spigler, R.B., Ranks, S.J. (2017). Phenotypic selection varies with pollination intensity across populations of Sabatia angularis. New Phytologist, 215(2):813-824. 
Forrest, J.R.K. (2014). Plant size, sexual selection, and the evolution of protandry in dioecious plants. The American Naturalist, 184(3):338-351.

Franks, S.J., Weis, A.E. (2009). Climate change alters reproductive isolation and potential gene flow in an annual plant. Evolutionary Applications, 2(4):481-488.

Galen, C., Stanton, M.L. (1991). Consequences of emergence phenology for reproductive success in Ranunculus adoneus. American Journal of Botany, 78(7):978-988.

Garcia, M.B., Ehrlen, J. (2002). Reproductive effort and herbivory timing in a perennial herb: Fitness components at the individual and population levels. American Journal of Botany, 89(8):1295-1302.

Ghazoul, J., Satake, A. (2009). Nonviable seed set enhances plant fitness: the sacrificial sibling hypothesis. Ecology, 90(2):369-377.

Gioria, M., Osborne, B.A. Pysek, P. (2018). Timing is everything: does early and late germination favor invasions by herbaceous alien plants? Journal of Plant Ecology, 11(1):4-16.

Graff, A. (1999). Population sex structure and reproductive fitness in gynodioecious Sidalcea malviflora. Evolution, 53(6):1714-1722. 
Gremer, J.R., Venable, D.L. (2014). Bet hedging in desert winter annual plants: Optimal germination strategies in a variable environment. Ecology Letters, 17(3):380-387.

Gross, K., Schiestl, F.P. (2015). Are tetraploids more successful? Floral signals, reproductive success and floral isolation in mixed-ploidy populations of a terrestrial orchid. Annals of Botany, 115(2):263-273.

Gorchov, D.L. (1988). Effects of pollen and resources on seed number and other fitness components in Amelanchier arborea (Rosaceae:Maloideae). American Journal of Botany, 75(9):1275-1285.

Halpern, S.L. (2005). Sources and consequences of seed size variation in Lupinus perennis (Fabaceae): Adaptive and non-adaptive hypotheses. American Journal of Botany, 92(2):205-213.

Hernandez-Cumplido, J., Forter, B., Benrey, B., Heil, M., Moreira, X. (2016). Induced floral and extrafloral nectar production affect ant-pollinator interactions and plant fitness. Biotropica, 48(3):342-348.

Hickman, J.C. (1975). Environmental unpredictability and plastic energy allocation strategies in Polygonum cascadense (Polygonaceae). Journal of Ecology, 63(2):689-701. 
Hoffmeister, M., Wittkopper, N., Junker, R.R. (2016). Herbivore-induced changes in ower scent and morphology affect the structure of owe-visitor networks but not plant reproduction. Oikos, 125(9):1241-1249.

Hove, A.A., Ivery, C.T., Mazer, S.J. (2016). Seed set variation in wild Clarkia populations: teasing apart the effects of seasonal resource depletion, pollen quality, and pollen quantity. Ecology and Evolution, 6(18):6524-6536.

Huang, Z., Tang, A., Footitt, S., Finch-Savage, W.E. (2018). Predicted global warming scenarios impact on the mother plant to alter seed dormancy and germination behaviour in Arabidopsis. Plant, Cell and Environment, 41(1):187-197.

Hughes, P.W., Simons, A.M. (2014). The continuum between semelparity and iteroparity: plastic expression of parity in response to season length manipulation in Lobelia inflata. BMC Evolutionary Biology, 14:90.

Hughes, P.W., Simons, A.M. (2014). Changing reproductive effort within a semelparous reproductive episode. American Journal of Botany, 101(8):1323-1331.

Hughes, P.W., Simons, A.M. (2014). Secondary reproduction in the herbaceous monocarp Lobelia inflata: time-constrained primary reproduction does not result in increased deferral of reproductive effort. BMC Ecology, 14:15. 
Jacobs, B.S., Lesmeister, S.A. (2012). Maternal environmental effects on fitness, fruit morphology and ballistic seed dispersal distance in an annual forb. Functional Ecology, 26(3):588-597.

Johnson, M.G., Shaw, A.J. (2016). The effects of quantitative fecundity in the haploid stage on reproductive success and diploid fitness in the aquatic peat moss Sphagnum macrophyllum. Heredity, 116(6):523-530.

Johnston, M.O. (1991). Pollen limitation of female reproduction in Lobelia Cardinalis and $L$. Siphilitica. Ecology, 72(4):1500-1503.

Johnston, M.O. (1992). Effects of cross and self-fertilization on progeny fitness in Lobelia cardinalis and L.Siphilitica. Evolution, 46(3):688-702.

Kalisz, S., Vogler, D.W., Hanley, K.M. (2004) Context-dependent autonomous self-fertilization yields reproductive assurance and mixed mating. Nature, 430:884-887.

Kang, H., Primack, R.B. (1991). Temporal variation of flower and fruit size in relation to seed yield in celandine poppy. American Journal of Botany, 78(5):711-722.

Karban, R., Strauss, S.Y. (1993). Effects of herbivores on growth and reproduction of their perennial host, Erigeron Glaucus. Ecology, 74(1):39-46. 
Kaspary, T.E., Cutti, L., Lamego, F.P. (2017). Growth, phenology, and seed viability between glyphosate-resistant and glyphosate-susceptible hairy fleabane. Bragantia, 76(1):92-101.

Kery, M., Matthies, D., Spillmann, H. (2000). Reduced fecundity and o spring performance in small populations of the declining grassland plants Primula veris and Gentiana lutea. Journal of Ecology, 88(1):17-30.

Kirk, H., Vrieling, K., Klinkhamer, P.G.L. (2005). Maternal effects and heterosis influence the fitness of plant hybrids. New Phytologist, 166(2):685-694.

Kooyers, N.J., Blackman, B.K., Holeski, L.M. (2017). Optimal defense theory explains deviations from latitudinal herbivory defense hypothesis. Ecology, 98(4):1036-1048.

Krupnick, G.A., Weis, A.E. (1999) The effect of floral herbivory on male and female reproductive success in Isomeris arborea. Ecology, 80(1):135-149.

Krupnick, G.A., Weis, A.E., Campbell, D.R. (1999). The consequences of floral herbivory for pollinator service to Isomeris arborea. Ecology, 80(1):125-134.

Labouche, A., Pannell, J.R., Richards, S.A. (2017). Effects of pollination intensity on offspring number and quality in a wind-pollinated herb. Journal of Ecology 105(1):197-208. 
Lehndal, L., Agren, J. (2015). Herbivory differentially affects plant fitness in three populations of the perennial herb Lythrum salicaria along a latitudinal gradient. PLoS One, 10(9).

Lemoine, N.P., Doublet, D., Burkepile, D.E., Parker, J.D., Salminen, J. (2017). Responses of plant phenology, growth, defense, and reproduction to interactive effects of warming and insect herbivory. Ecology, 98(7):1817-1828.

Li, H., Lindquist, J.L., Yang, Y. (2015). Effects of sowing date on phenotypic plasticity of fitness-related traits in two annual weeds on the Songnen plain of China. PLoS One, 10(5).

Li, X.M., She, D.Y., Zhang, D.Y., Liao, W.J. (2015). Life history trait differentiation and local adaptation in invasive populations of Ambrosia artemisiifolia in China. Oecologia, 177(3):669-677.

Lienert, J., Fischer, M. (2004). Experimental inbreeding reduces seed production and germination independent of fragmentation of populations of Swertia perennis. Basic and Applied Ecology, 5(1):43-52.

Lobo, J.A., Jimenez, D., Fuchs, E.J., Solis-Hernandez, W. (2015). Lack of early inbreeding depression and distribution of selfing rates in the neotropical emergent tree Ceiba pentandra: Assessment from several reproductive events. American Journal of Botany, 102(6):983-991. 
Lortie, C.J., Aarssen, L.W. (1999). The advantage of being tall: Higher flowers receive more pollen in Verbascum thapsus L. (Scrophulariaceae). Ecoscience, 6(1):68-71.

Lu, J.J., Baskin, C.C., Tan, D.Y., Baskin, J.M. (2016). Effects of germination season on life history traits and on transgenerational plasticity in seed dormancy in a cold desert annual. Scientific Reports, 6.

Martinkova, J., Klimesova, J.(2016). Enforced Clonality Confers a Fitness Advantage. Frontiers in Plant Science, 7:2.

May, J.D., Killingbeck, K.T. (1995). Effects of herbivore-induced nutrient stress on correlates of fitness and on nutrient resorption in scrub oak (Quercus ilicifolia). Canadian Journal of Forest Research, 25(11):1858-1864.

Maron, J.L., Agrawal, A.A., Hastings, A.P., Johnson, M.T.J. (2018). Fitness consequences of occasional outcrossing in a functionally asexual plant (Oenothera biennis). Ecology, 99(2): 464-473.

McArt, S.H., Salminen, J.P., Thaler, J.S., Halitschke, R. (2012) Leaf herbivory increases plant fitness via induced resistance to seed predators. Ecology, 94(4):966-975. 
Metcalf, C.J.E., Coons, D.N., Burghardt L. (2015). Avoiding the crowds: the evolution of plastic responses to seasonal cues in a density-dependent world. Journal of Ecology, 103(4):819828.

Metz, J., von Oppen, J., Tielborger, K. (2015). Parental environmental effects due to contrasting watering adapt competitive ability, but not drought tolerance, in offspring of a semi-arid annual Brassicaceae. Journal of Ecology, 103(4).

Mitchell-Odds, T., Waller, D.M. (1995) Relative performance of selfed and outcrossed progeny in Impatiens capensis. Evolution, 39(3):533-544.

Montalvo, A.M. (1994) Inbreeding depression and maternal effects in Aquilegia Caerulea, a partially selfing plant. Ecology, 75(8):2395.

Moreira, X., Mooney, K.A., Abdala-Roberts, L., Linhart, Y.B. (2015). Effects of climate on reproductive investment in a masting species: assessment of climatic predictors and underlying mechanisms. Journal of Ecology, 103(5).

Nagamitsu, T., Kubo, T., Mori, Y. (2008) Clonal growth and its effects on male and female reproductive success in Prunus ssiori (Rosaceae). Population Ecology, 51(1):175-186.

Mothershead, K., Marquis, R.J. (2000). Fitness impacts of herbivory through indirect effects on plant-pollinator interactions in Oenothera macrocarpa. Ecology, 81(1): 30-40. 
Munzbergova, Z., Skuhrovec, J. (2017). Contrasting effects of ploidy level on seed production in a diploid-tetraploid system. AoB Plants, 9(1).

Mutikainen, P., Delph, L.F. (1998). Inbreeding depression in gynodioecious Lobelia siphilitica: Among-family differences override between-morph differences. Evolution, 52(6):15721582.

Nagamitsu, T., Futamura, N. (2014). Sex expression and inbreeding depression in progeny derived from an extraordinary hermaphrodite of Salix subfragilis. Botanical Studies, $55(1)$.

Nuortila, C., Tuomi, J., Kytoviita, M.M. (2004). Mycorrhizal symbiosis has contrasting effects on fitness components in Campanula rotundifolia. New Phytologist, 164(3):543-553.

Parachnowitsch, A.L., Kessler, A. (2010). Pollinators exert natural selection on flower size and floral display in Penstemon digitalis. New Phytologist, 188(2):393-402.

Pearse, I.S., Aguilar, J., Schroder, J., Strauss, S.Y. (2017). Macroevolutionary constraints to tolerance: trade-offs with drought tolerance and phenology, but not resistance. Ecology, 98(11):2758-2772. 
Preite, V., Armbruster, G.F.J., Scheepens, J.F., Stocklin, J. (2015). Adaptation of flowering phenology and fitness-related traits across environmental gradients in the widespread Campanula rotundifolia. Evolutionary Ecology, 29(2): 249-267.

O’Connell, L.M., Johnston, M.O. (1998). Male and female pollination success in a deceptive orchid, a selection study. Ecology, 79(4).

Rademaker, M.C.J., De Jong, T. (1999). The shape of the female fitness curve for Cynoglossum officinale: Quantifying seed dispersal and seedling survival in the field. Plant Biology, $1(3): 351-356$.

Reusch, T. (2001). Fitness-consequences of geitonogamous selfing in a clonal marine angiosperm (Zostera marina). Journal of Evolutionary Biology, 14(1).

Rivkin, L.R., Case, A.L., Caruso, C.M. (2015). Frequency dependent fitness in gynodecious Lobelia siphilitica. Evolution, 69(5):1232-1243.

Rocha, O.J., Gomez, C., Trapnell, D.W., Macaya, G., Hamrick, J.L., Smouse, P.E. (2018). Reproductive consequences of variation in flowering phenology in the dry forest tree Enterolobium cyclocarpum in Guanacaste, Costa Rica. American Journal of Botany, 105(12): 2037-2050. 
Setsuko, S., Tomaru, N. (2011). The effects of plant size and light availability on male and female reproductive success and functional gender in a hermaphrodite tree species, Magnolia stellate. Botany, 89(9):593-604.

Simons, A.M. (2007). Selection for increased allocation to offspring number under environmental unpredictability. Journal of Evolutionary Biology, 20(2): 813-7.

Simons, A.M., Johnston, M.O. (2000). Variation in seed traits of Lobelia inflata (Campanulaceae): Sources and fitness consequences. American Journal of Botany, 87(1): $124-32$.

Simons, A.M., Johnston, M.O. (2003). Suboptimal timing of reproduction in Lobelia inflata may be a conservative bet-hedging strategy. Journal of Evolutionary Biology, 16(2):233-43.

Simons, A.M., Johnston, M.O. (2006). Environmental and genetic sources of diversification in the timing of seed germination: Implications for the evolution of bet hedging. Evolution, 60(11): 2280-92.

Stanton, M.L., Young, H., Clegg, J.M, Ellstrand, N.C. (1991) Consequences of floral variation for male and female reproduction in experimental populations of wild radish, Raphanus sativus L. Evolution, 45(2): 268-280. 
Stanton, M.L., Preston, R.E. (1988). Ecological consequences and phenotypic correlates of petal size variation in wild radish, Raphanus sativus (Brassicaceae). American Journal of Botany, 75(4): 528-539.

Sulis, E., Cogoni, D., Bacchetta, G. (2017). Reproductive performance of Helianthemum caputfelis along its fragmented distribution in the Mediterranean coasts. Flora, 234: 24-33.

Sutherland, S., Delph, L.F. (1984). On the importance of male fitness in plants: Patterns of fruitset. Ecology, 65(4): 1093-1104.

Taylor, M.A., Cooper, M.D., Braun, P., Sellamuthu, R. (2017). Interacting effects of genetic variation for seed dormancy and flowering time on phenology, life history, and fitness of experimental Arabidopsis thaliana populations over multiple generations in the field. New Phytologist, 216(1).

Thompson, K.A., Johnson, M.T. (2016). Antiherbivore defenses alter natural selection on plant reproductive traits. Evolution, 70(4): 796-810.

Van Drunen, W.E., Dorken, M.E. (2012). Trade-offs between clonal and sexual reproduction in Sagittaria latifolia (Alismataceae) scale up to affect the fitness of entire clones. New Phytologist, 196(2): 606-616. 
Van Drunen, W.E., Dorken, M.E., van Kleunen, M. (2015). Consequences of clonality for sexual fitness: Clonal expansion enhances fitness under spatially restricted dispersal. Proceedings of the National Academy of Sciences of the United States of America, 112(29): 8929-36.

Van Loon, J.J.A., De Boer, J.G., Dicke, M. (2000). Parasitoid-plant mutualism: parasitoid attack of herbivore increases plant reproduction. Entomologia Experimentalis et Applicata, 97: 219-227.

Vogler, D.W., Stephenson, A.G., Peretz, S. (1999). Floral plasticity in an iteroparous plant: The interactive effects of genotype, environment, and ontogeny in Campanula rapunculoides (Campanulaceae). American Journal of Botany, 86(4): 482-94.

Vogler, D.W., Stephenson, A., Filmore. (1999). Inbreeding depression in Campanula rapunculoides L. I. A comparison of inbreeding depression in plants derived from strong and weak self-incompatibility phenotypes. Journal of Evolutionary Biology, 12(3): 483494.

Volis, S. (2007). Correlated patterns of variation in phenology and seed production in populations of two annual grasses along an aridity gradient. Evolutionary Ecology, 21(3): 381-393. 
Waser, N.M., Price, M.V., Shaw, R.G. (1995). Seed set and seed mass in Ipomopsis aggregata: Variance partitioning and inferences about postpollination selection. Evolution, 49(1): $80-88$.

Weis, A.E., Sekor, M., Franks, S.J., Wadgymar, S.M (2014). The shape of selection: using alternative fitness functions to test predictions for selection on flowering time. Evolutionary Ecology, 28(5): 885-904.

Weis, A., Petro, B., Austen, E.J., Turner, K.M. (2015). Hard and soft selection on phenology through seasonal shifts in the general and social environments: A study on plant emergence time. Evolution, 69(6).

Wheeler, J.A., Cortes, A.J., Sedlacek, J., Karrenberg, S. (2016). The snow and the willows: earlier spring snowmelt reduces performance in the low-lying alpine shrub Salix herbacea. Journal of Ecology, 104(4): 1041-1050.

Williams, C.F., Drew, A., Kuchenreuther, M.A. (2000). Floral dimorphism, pollination, and selffertilization in gynodioecious Geranium richardsonii (Geraniaceae). American Journal of Botany, 87(5): 661-9.

Xi, X., Eisenhauer, N., Sun, S. (2015). Parasitoid wasps indirectly suppress seed production by stimulating consumption rates of their seed-feeding hosts. Journal of Animal Ecology, 84(4). 
Young, H.J., Stanton, M.L. (1990). Influences of floral variation on pollen removal and seed production in wild radish. Ecology, 71(2): 536-547.

Zimmerman, M., Ronald, S.G. (1984). The relationship between flowering phenology and seed set in an herbaceous perennial plant, Polemonium foliosissimum gray. American Midland Naturalist, 111(1): 185.

Zust, T., Agrawal, A.A, Rasmann, S. (2015). Growth-defense tradeoffs for two major antiherbivore traits of the common milkweed Asclepias syriaca. Oikos, 124(10): 1404-1415. 


\section{Appendix B Supporting data for the effects of salinity on germination and seed yield of Lobelia inflata}

Analysis of fitness variation under laboratory conditions is notoriously problematic because even individuals that would have low fitness in the field perform well under benign laboratory conditions (St Juliana and Janzen, 2007). Seed number is often used as a surrogate for fitness, but under lab conditions, variance in seed fitnessmeasured as variance in seed germination and viability- may be much reduced. In order to introduce variation in seed fitness under laboratory conditions, an abiotic stress such as salinity can be used (Vu et al., 2015; Hannachi and Van Labeke 2018). Salinity is known to be one of the major abiotic stresses that affect plant growth. Seed germination and seedling growth are the stages most sensitive to salinity, where germination or survival of seeds are often delayed or prevented (Papastylianou et al., 2017). The goal of this study was to investigate laboratory conditions under which seed germination and viability better reflect variable seed fitness, by using varying levels of salinity. Lobelia inflata seeds and new seedlings will be subjected to salinity conditions that are harsh enough to reveal fitness differences, but not so harsh that mortality is $100 \%$.

Two fitness assays were performed: 1) seed viability (germination assay) and, 2) seedling survival. Forty-eight randomly selected seeds from eight genotypes were used per treatment. To account for true fitness differences, four genotypes that were "fit" and four genotypes that were "less fit" were used. In order to estimate fitness for these genotypes, 30 seeds were randomly selected from each genotype and measured for seed 
size. Because seed size known to affect the fitness of the offspring (i.e. larger seeds often have higher fitnesses) (Giles, 1990; Mandal, 2008; Souza, 2014), the mean seed size for the thirty seeds were used to categorize "fit" and "unfit" genotypes; the larger the mean seed size, the more "fit" the genotype.

For the germination assay, seeds were cold stratified for 14 days and then subjected to varying concentrations of a $\mathrm{NaCl}$ solution. Four treatments were used, each with different concentrations of $\mathrm{NaCl}$ :

\section{Salinity treatments:}

1) Control (no $\mathrm{NaCl})$

2) Treatment 1: seeds treated with $0.01 \mathrm{M} \mathrm{NaCl}(292.2 \mathrm{mg} / 500 \mathrm{~mL})$

3) Treatment 2: seeds treated with $0.05 \mathrm{M} \mathrm{NaCl}(1.461 \mathrm{~g} / 500 \mathrm{~mL})$

4) Treatment 3: seeds treated with $0.1 \mathrm{M} \mathrm{NaCl}(2.922 \mathrm{~g} / 500 \mathrm{~mL})$

5) Treatment 4: seeds treated with $0.15 \mathrm{M} \mathrm{NaCl}(4.383 \mathrm{~g} / 500 \mathrm{~mL})$

Seeds were initially watered with $\mathrm{NaCl}$ solutions, and then watered with distilled water henceforth. Germinated seeds were counted daily for 31 days. Germination was considered successful when a $2 \mathrm{~mm}$ radicle is visible. Seeds that did not germinate after 31 days were considered unviable. The final germination percentage and mean germination time were concluded for analyses. Non-germinating seeds were subjected to a cold stratification process for two weeks to test for dormancy, and then re-tested for germination under no $\mathrm{NaCl}$ treatment. 
For the second part of the fitness assay, seedlings were planted in cell-packs $(4 \mathrm{~cm}$ $\mathrm{x} 4 \mathrm{~cm}$ ) in 32-celled trays with autoclaved soil (Promix 860B) in a randomized fashion. Trays were then transferred to Biochambers AC-40 set on a 16h/8h day/night photoperiod schedule at $24^{\circ} \mathrm{C}$ to induce growth. The four salinity treatments were applied at the beginning of seedling transplant. Survival of seedlings (either alive or dead) was observed for 20 days and rosette size measurements were taken every 3 days.

The first stage of the fitness assay revealed that germination did not significantly differ between treatments $(\mathrm{F}(5,42)=0.5733, \mathrm{P}=0.597)$; mean germination percentage ranged from $97.5 \%$ to $100 \%$ for all treatments, regardless of seed size. All nongerminating seeds successfully germinated after a second trial.

The second stage of the fitness assay showed that survival differed between treatments; seedling survival decreased with higher salinity concentrations control (seedling survival $\%=93.5$ ), treatment 1 (seedling survival $\%=88.125$ ), treatment 2 (seedling survival $\%=81.5$ ), treatment 3 (seedling survival $\%=71.875$ ), treatment 4 (seedling survival $\%=55.25$ ). Treatment 3 in particular produced the most variable results out of all the treatments among all genotypes, where survivability ranged from $45 \%$ to $81 \%$. Thus, treatment $3(0.1 \mathrm{M} \mathrm{NaCl})$ was determined to be the most effective in determining true fitness differences and was used in the main experiment. 